\title{
Developmental Changes in AMPA and Kainate Receptor- Mediated Quantal Transmission at Thalamocortical Synapses in the Barrel Cortex
}

\author{
Neil J. Bannister, ${ }^{1}$ Timothy A. Benke, ${ }^{2}$ Jack Mellor, ${ }^{1}$ Helen Scott, ${ }^{1}$ Esra Gürdal,,${ }^{1,3}$ John W. Crabtree, ${ }^{1}$ and \\ John T. R. Isaac ${ }^{1,4}$ \\ ${ }^{1}$ Medical Research Council Centre for Synaptic Plasticity, Department of Anatomy, University of Bristol, Bristol BS8 1TD, United Kingdom, ${ }^{2}$ Department of \\ Pediatrics, University of Colorado Health Sciences Center, Denver, Colorado 80262, ${ }^{3}$ Department of Anatomy, Marmara University School of Medicine, \\ Haydarpasa 34668, Istanbul, Turkey, and ${ }^{4}$ National Institute of Neurological Disorders and Stroke, National Institutes Health, Bethesda, Maryland 20892
}

\begin{abstract}
During the first week of life, there is a shift from kainate to AMPA receptor-mediated thalamocortical transmission in layer IV barrel cortex. However, the mechanisms underlying this change and the differential properties of AMPA and kainate receptor-mediated transmission remain essentially unexplored. To investigate this, we studied the quantal properties of AMPA and kainate receptor-mediated transmission using strontium-evoked miniature EPSCs. AMPA and kainate receptor-mediated transmission exhibited very different quantal properties but were never coactivated by a single quantum of transmitter, indicating complete segregation to different synapses within the thalamocortical input. Nonstationary fluctuation analysis showed that synaptic AMPA receptors exhibited a range of singlechannel conductance $(\gamma)$ and a strong negative correlation between $\gamma$ and functional channel number, indicating that these two parameters are reciprocally regulated at thalamocortical synapses. We obtained the first estimate of $\gamma$ for synaptic kainate receptors $(<2 \mathrm{pS})$, and this primarily accounted for the small quantal size of kainate receptor-mediated transmission. Developmentally, the quantal contribution to transmission of AMPA receptors increased and that of kainate receptors decreased. No changes in AMPA or kainate quantal amplitude or in AMPA receptor $\gamma$ were observed, demonstrating that the developmental change was attributable to a decrease in the number of kainate synapses and an increase in the number of AMPA synapses contributing to transmission. Therefore, we demonstrate fundamental differences in the quantal properties for these two types of synapse. Thus, the developmental switch in transmission will dramatically alter information transfer at thalamocortical inputs to layer IV.
\end{abstract}

Key words: glutamate; synaptic transmission; layer IV; neocortex; miniature EPSC; nonstationary fluctuation analysis

\section{Introduction}

Fast excitatory synaptic transmission in the mammalian CNS is mediated predominately by the AMPA, NMDA, and kainate type ionotropic glutamate receptors (Hollmann and Heinemann, 1994). Kainate receptors are widely expressed in the mammalian brain, but their physiological roles are poorly understood because of a lack, until recently, of selective ligands and genetic tools. Studies so far have indicated roles for kainate receptors in longterm potentiation (LTP), in regulating circuit excitability, and in epilepsy (Frerking and Nicoll, 2000; Schmitz et al., 2001; Kullmann, 2001; Lerma et al., 2001; Lerma, 2003).

At developing thalamocortical inputs in barrel cortex, both presynaptic and postsynaptic kainate receptors are activated by

Received Feb. 27, 2004; revised April 19, 2005; accepted April 19, 2005

This work was supported by the Wellcome Trust (J.M., J.T.R.I.), National Institutes of Health Grant NS 41267 (T.A.B.), and the National Institute of Neurological Disorders and Stroke (J.T.R.I.). We thank Josh Lawrence and Chris McBain for their advice on the voltage-jump experiments and the University of Bristol Medical Research Council Cell Imaging Centre.

Correspondence should be addressed to John Isaac, National Institute of Neurological Disorders and Stroke/ National Institutes of Health, 35 Convent Drive, Bethesda, MD 20892. E-mail: isaacj@ninds.nih.gov. D01:10.1523/JNEUROSCI.0827-05.2005

Copyright $\odot 2005$ Society for Neuroscience $\quad$ 0270-6474/05/255259-13\$15.00/0 synaptically released glutamate (Kidd and Isaac, 1999, 2001; Kidd et al., 2002). The kainate receptor-mediated EPSC evoked at this input exhibits slow kinetics, similar to that observed at other synapses (Castillo et al., 1997; Vignes and Collingridge, 1997; Cossart et al., 1998; Frerking et al., 1998; Li and Rogawski, 1998; Li et al., 1999; Bureau et al., 2000). The thalamocortical kainate receptor-mediated EPSC can be readily separated from the AMPA receptor (AMPAR)-mediated component of transmission both pharmacologically and kinetically (Kidd and Isaac, $1999,2001)$. An interesting feature of transmission in barrel cortex is that studies so far suggest that AMPA and kainate receptors do not colocalize at the same synapses (Kidd and Isaac, 1999). During development, the relative contribution of the kainate receptor-mediated component to transmission decreases, and this is paralleled by an increase in the AMPA receptor-mediated component, a change that can also be rapidly produced by NMDA receptor-dependent LTP (Kidd and Isaac, 1999).

The synaptic mechanisms underlying the developmental change from kainate to AMPA receptor-mediated transmission are essentially unexplored. Moreover, what determines the differential properties of AMPA and kainate receptor-mediated transmission at this input are unclear. To investigate these issues, 
we studied the quantal and single-channel properties of kainate and AMPA receptor-mediated transmission at thalamocortical synapses onto layer IV neurons in developing barrel cortex [postnatal day 2 (P2) to P9], using $\mathrm{Sr}^{2+}$-evoked miniature EPSCs (mEPSCs). We find that, although both kainate and AMPA receptors mediate quantal transmission, they do so completely independently and have very different quantal and single-channel properties. Developmentally, there is a decrease in the quantal contribution of kainate receptor-mediated transmission and a reciprocal increase in the quantal contribution of AMPA receptor-mediated transmission. No developmental change is observed in the quantal size of these two types of transmission or in AMPA receptor single-channel properties. These findings provide the first detailed comparison of the quantal and singlechannel properties of AMPA and kainate receptor-mediated transmission in developing neocortex. Our findings indicate that kainate and AMPA receptor-mediated synaptic transmission confer very different properties on thalamocortical synapses and that the relative contributions of these two types of synapse change during development. Thus, the developmental shift from kainate to AMPA receptor-mediated transmission in the barrel cortex will dramatically alter the information processing properties of the thalamocortical input to layer IV.

\section{Materials and Methods}

Electrophysiology. Thalamocortical slices (Agmon and Connors, 1991) were prepared from mouse pups aged between postnatal days 2 and 9 (day of birth is postnatal day 0 ) as described previously (Kidd and Isaac, 1999; Kidd et al., 2002). Slices were superfused with an extracellular solution of the following composition (in $\mathrm{mM}$ ): $119 \mathrm{NaCl}, 2.5 \mathrm{KCl}, 1.0$ $\mathrm{NaH}_{2} \mathrm{PO}_{4}, 26.2 \mathrm{NaHCO}_{3}, 2.5 \mathrm{CaCl}_{2}, 1.3 \mathrm{MgSO}_{4}$, and 11 glucose [saturated with $95 \% \mathrm{O}_{2} / 5 \% \mathrm{CO}_{2}$ at room temperature $\left.\left(22-25^{\circ} \mathrm{C}\right)\right]$. D-AP-5 $(50 \mu \mathrm{M})$ and picrotoxin (PTX) $(100 \mu \mathrm{M})$ were included in the extracellular solution to block NMDA and $\mathrm{GABA}_{\mathrm{A}}$ receptors, respectively. Barrels were visualized using infrared differential interference contrast (DIC) optics under low-power magnification (see Fig. 1 A). In P4 animals and older, we could reliably visualize barrels using this method. In P2 and P3 animals, layer IV barrel cortex appeared as a dense band of cells, which was the superficial layer; layer $\mathrm{V}$ was the layer immediately below this, identified because it contains large pyramids. Cells in layer IV in P2 and P3 animals received thalamocortical input. Whole-cell patch-clamp recordings were made from visually identified neurons in barrels in layer IV (see Fig. $1 B$ ) using an intracellular solution of the following composition (in mM): $135 \mathrm{CsMeSO}_{4}, 8 \mathrm{NaCl}, 10$ HEPES, 5 QX-314 [N(2,6-dimethylphenylcarbamoylmethyl)triethylammonium chloride], 0.5 EGTA, $4 \mathrm{Mg}$-ATP, and 0.3 Na-GTP, pH 7.2 (285 mOsm). Thalamocortical EPSCs were evoked by low-frequency $(0.05-0.1 \mathrm{~Hz})$ extracellular stimulation of the ventrobasal thalamus at a holding potential of -70 $\mathrm{mV}$ as described previously (Agmon and Connors, 1991; Feldman et al., 1998; Kidd and Isaac, 1999; Kidd et al., 2002). The junction potential $(\sim 5 \mathrm{mV})$ was not corrected for. For cells filled with biocytin, a concentration of $0.4 \%$ biocytin in the whole-cell solution was used, and recordings were obtained for at least $20 \mathrm{~min}$. Slices were subsequently fixed in $4 \%$ paraformaldehyde, and cells were visualized using the $\mathrm{ABC}-\mathrm{DAB}$ method (Crabtree and Isaac, 2002). For excised patches, a whole-cell recording was first obtained, and EPSCs were collected. An outside-out patch was then pulled, and a $3 \mathrm{~ms}$ pulse of $10 \mathrm{~mm}$ glutamate was rapidly applied using continuous patch perfusion by theta capillary tube attached to a piezo-driven rapid solution exchange system (Lester et al., 1990; Colquhoun et al., 1992). Glutamate-evoked currents were recorded at a holding potential of $-70 \mathrm{mV}$ in the presence of $1.3 \mathrm{mM} \mathrm{Mg}^{2+}$ in all external solutions. Exchange time was $<400 \mu$ s for complete exchange (150 $\mu$ s for $20-80 \%$ exchange time) as estimated using open tip currents. Data were recorded using an Axopatch 200B amplifier (Molecular Devices, Union City, CA), filtered at $5 \mathrm{kHz}$, and acquired and digitized at $20 \mathrm{kHz}$ using Signal software (Cambridge Electronic Design,
Cambridge, UK). EPSC amplitude, direct current, input resistance, and series resistance were measured on-line. Series resistance was estimated as described previously (Kidd and Isaac, 1999), and cells in which series resistance changed by $>20 \%$ were rejected.

Voltage-jump experiments. In a subset of cells, we performed voltagejump experiments using a methodology as described previously (Walker et al., 2002). Dual-component evoked EPSCs (eEPSCs) were recorded at a holding potential of $-60 \mathrm{mV}$, and, at various times during the recording, the holding potential was stepped to $-90 \mathrm{mV}$. To analyze the fast AMPA receptor-mediated component of the EPSC, voltage jumps were initiated from 4-5 ms before EPSC onset to 8-9 ms after EPSC onset, with an interval of $0.5 \mathrm{~ms}$ between jumps. For the slower kainate receptor-mediated component, voltage jumps were made between 18 and $108 \mathrm{~ms}$ after the onset of the EPSC, with an interval of $10 \mathrm{~ms}$ between voltage jumps. The order of the voltage jumps were randomized to control for any systematic change in the amplitude of the EPSC over time. For each voltage jump, an interleaved jump in the absence of a synaptic current was obtained and used to subtract the capacitance artifact. At least five repeats of each voltage step (at each time point) were obtained for each cell analyzed. In some cells, $>5$ repeats were obtained; however, the difficulty in maintaining long recordings and the stability of axons in response to the long epoch of stimulation in these neonatal slices prevented greater numbers of repeats being obtained in many cells. After removal of capacitance artifacts, the traces were averaged for each time step. For the fast AMPA receptor-mediated component of the EPSC, the area under the EPSC was calculated using a $20 \mathrm{~ms}$ time window, and charge recovery curves were plotted as described previously (Häusser and Roth, 1997; Walker et al., 2002). The charge recovery data were fit with a sigmoidal relationship simplified from Häusser and Roth (1997) as used by Walker et al. (2002), from which the time course of the synaptic conductance and the electrotonic index of the synapse were derived. For the slow kainate receptor-mediated component of the EPSC, the signalto-noise ratio was not sufficient to allow fitting of the data with the sigmoidal charge recovery relationship, precluding estimation of the electrotonic index and quantification of time course of the synaptic conductance. However, the amount of kainate receptor-mediated charge recovered was estimated by calculating the difference between the predicted exponential decay of the kainate receptor-mediated component and the peak of the recovered response at $-90 \mathrm{mV}$.

Modeling. The passive electrical properties of a layer IV barrel cortex stellate neuron were simulated using a similar approach as described previously (Benke et al. 2001). A compartmental model based on biocytin-filled immature layer IV stellate neurons (see Fig. 1C) and previously reconstructed adult layer IV stellate neurons (Bannister et al., 2002) with attached somatic patch electrode was used with a total of 63 compartments: an explicit dendrite with 46 compartments, 3 synaptic spines, with 3 compartments each, and a soma with 4 compartments, 4 lumped dendritic segments with 1 compartment each (see Fig. 6A). Maximal compartment length along the explicit dendrite containing dendritic spines was $10 \mu \mathrm{m}$ (except for "extreme" simulations). The soma was $10 \mu \mathrm{m}$ in diameter. The explicit dendritic diameter tapered from 1.3 to $0.5 \mu \mathrm{m}$. Spine heads (a single compartment) measured $0.5 \mu \mathrm{m}$ in diameter and $0.3 \mu \mathrm{m}$ in length, and spine shafts (two compartments) measured $0.1 \mu \mathrm{m}$ in diameter and $0.3 \mu \mathrm{m}$ in length. Lumped dendritic segment size was $96 \mu \mathrm{m}$ in length with a diameter of $1.1 \mu \mathrm{m}$, assuming an equivalent finite length cylinder. The resulting tip-to-tip distance across the soma using the optimized lumped dendritic length was $177 \mu \mathrm{m}$. Membrane current output as recorded from the simulated patch electrode was filtered at $2 \mathrm{kHz}$.

The passive electrical properties and size of the lumped dendrites of the modeled neuron were optimized to fit a typical somatically recorded membrane current transient template (in response to a $5 \mathrm{mV}$ depolarizing voltage step from $-70 \mathrm{mV}$ ) using a genetic algorithm (Taylor and Enoka, 2004). A mutation rate of 0.2 and a crossover rate of 0.6 were used. Solutions converged with a stable error over 100 generations after 400-500 generations. The resulting parameter fits obtained (Table 1) using the genetic algorithm were superior to those obtained using a more typical simplex algorithm and represent a unique solution for the ranges 
Table 1. Parameter fits obtained

\begin{tabular}{lllll}
\hline & Simplex & Genetic & Genetic range & Units \\
\hline Series resistance $\left(R_{\mathrm{s}}\right)$ & 20 & 24.7 & $20-70$ & $\mathrm{M} \Omega$ \\
Axial resistance $\left(R_{\mathrm{a}}\right)$ & 350 & 340 & $20-350$ & $\Omega \mathrm{cm}$ \\
Membrane capacitance $\left(C_{\mathrm{m}}\right)$ & 0.65 & 0.68 & $0.6-1.15$ & $\mu \mathrm{F} / \mathrm{cm}^{2}$ \\
Membrane resistance $\left(R_{\mathrm{m}}\right)$ & 21.7 & 20.1 & $0.1-1,000,000$ & $\mathrm{k} \Omega \mathrm{cm}^{2}$ \\
Dendritic factor & 1.62 & 1.48 & $1.1-3.5$ & $\mathrm{No} \mathrm{units}$ \\
Lumped dendritic diameter & 1.3 & 1.44 & $0.4-3.0$ & $\mu \mathrm{m}$ \\
Lumped dendritic length & 80 & 67 & $20-1000$ & $\mu \mathrm{m}$ \\
Total error & 95.8 & 59.4 & & $\mathrm{pA}^{2}$ \\
\hline
\end{tabular}

Table 2. Resulting parameters for the models

\begin{tabular}{llll}
\hline & Realistic & Extreme & Units \\
\hline$R_{\mathrm{s}}$ & 26.3 & 26.4 & $\mathrm{M} \Omega$ \\
$R_{\mathrm{a}}$ & 340 & 163 & $\Omega \mathrm{cm}$ \\
$R_{\mathrm{m}}$ & 47.5 & 4902 & $\mu \mathrm{F} / \mathrm{cm}^{2}$ \\
$C_{\mathrm{m}}$ & 0.64 & 0.67 & $\mathrm{k} \Omega \mathrm{cm}^{2}$ \\
Dendritic factor & 3.5 & 2.0 & $\mathrm{No} \mathrm{units}$ \\
Lumped dendritic diameter & Not used & 1.2 & $\mu \mathrm{m}$ \\
Lumped dendritic length & Not used & 63 & $\mu \mathrm{m}$ \\
Length parameter & Not used & 7.94 & $\mathrm{No} \mathrm{units}$ \\
Average total error & 32.2 & 1.4 & $\mathrm{pA}^{2}$ \\
\hline
\end{tabular}

of parameters implemented (Youngs, 2002); these parameters were used in subsequent kinetic modeling studies.

To address whether passive filtering could account for slow synaptic currents, optimization of these same parameters using the genetic algorithm was performed with multiple templates: the typical somatically recorded membrane current transient template, an $\mathrm{EPSC}_{\text {fast }}$ template ( $\tau_{\text {rise }} 0.9 \mathrm{~ms}, t_{\text {decay }} 4.1 \mathrm{~ms}$ ) for proximal synapse 1 , and an $\mathrm{EPSC}_{\text {slow }}$ template $\left(\tau_{\text {rise }} 2 \mathrm{~ms}, t_{\text {decay }} 50 \mathrm{~ms}\right.$ ) for distal synapse 3 . A synaptic current

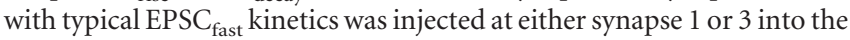
passive membrane model. The resulting parameters for this "realistic" model are shown in Table 2. With the addition of a length parameter (range, 0.1-10), which expanded (or contracted) the length of each compartment in the explicit dendrite, alternative geometries that might allow better optimization were explored with the genetic algorithm. The resulting parameters for this extreme model are also shown in Table 2.

The passive membrane model was coupled to detailed kinetic models of AMPA or kainate receptor currents generated at synaptic spine heads at variable distances from the soma, as described previously (Benke et al., 2001). AMPA and kainate receptor channels were modeled with a typical macroscopic kinetic scheme (Diamond and Jahr, 1997) (see Fig. 6A). Rate constants for AMPA receptors were as published, except the closing rate $(\beta)$ was adjusted slightly to match kinetics observed with voltagejump experiments. AMPA receptor single-channel conductance was chosen to be similar to experimental data. Rate constants for kainate receptors were empiric modifications of AMPA receptor rate constants, which increased the affinity by 250 -fold and reduced overall desensitization to result in synaptic currents with kinetics similar to those obtained experimentally. Average characteristics of stochastic AMPA and kainate receptors, simulated with the Monte Carlo technique in response to a 3.5 mM glutamate pulse with a peak time of $2 \mu$ s and decay time of $1 \mathrm{~ms}$, are summarized in Table 3. Background noise of $1.2 \mathrm{pA}$ root mean square was added, to simulate experimental noise. A typical mean AMPA receptor current is overlain with experimental data in Figure 6B; a typical mean kainate receptor current is overlain with experimental data in Figure $6 \mathrm{H}$. Both show good agreement. Ensembles of either AMPA or kainate receptor synaptic currents, at multiple synaptic locations (perfectly clamped, $0,15,31,50,77$, and $100 \mu \mathrm{m}$ ) from the soma, were then analyzed as described for the experimental data.

Analysis of experimental data. Paired-pulse ratio was calculated by dividing the averaged peak amplitude of the second EPSC $\left(\right.$ EPSC $\left._{2}\right)$ by the averaged amplitude of the first EPSC $\left(\right.$ EPSC $\left._{1}\right)$. The amplitude of EPSC 2 was estimated by measuring the difference between the peak of EPSC $_{2}$ and the current immediately before onset of EPSC 2 . Fast and slow
Table 3. Average characteristics of stochastic AMPA and kainate receptors simulated with the Monte Carlo technique

\begin{tabular}{lll}
\hline & AMPA & Kainate \\
\hline$k_{+1}(\mathrm{~m} / \mathrm{s})$ & $2.66 \times 10^{7}$ & $2.66 \times 10^{7}$ \\
$k_{-1}\left(\mathrm{~s}^{-1}\right)$ & $6.24 \times 10^{3}$ & $6.24 \times 10^{3} / 250$ \\
$k_{+2}(\mathrm{~m} / \mathrm{s})$ & $1.33 \times 10^{7}$ & $1.33 \times 10^{7}$ \\
$k_{-2}\left(\mathrm{~s}^{-1}\right)$ & $1.25 \times 10^{4}$ & $1.25 \times 10^{4} / 250$ \\
$k_{+3}\left(\mathrm{M} / \mathrm{s}^{1}\right)$ & $1.33 \times 10^{7}$ & 0.00001 \\
$k_{-3}\left(\mathrm{~s}^{-1}\right)$ & $6.24 \times 10^{3}$ & 0.00001 \\
$\alpha\left(\mathrm{s}^{-1}\right)$ & $5.7 \times 10^{3}$ & $1.0 \times 10^{3}$ \\
$\beta\left(\mathrm{s}^{-1}\right)$ & $8.0 \times 10^{2}$ & $4.0 \times 10^{2}$ \\
$\alpha_{1}\left(\mathrm{~s}^{-1}\right)$ & 20.0 & 0.00001 \\
$\beta_{1}\left(\mathrm{~s}^{-1}\right)$ & 361.0 & 0.00001 \\
$\alpha_{2}\left(\mathrm{~s}^{-1}\right)$ & 18.0 & 0.00001 \\
$\beta_{2}\left(\mathrm{~s}^{-1}\right)$ & 650.0 & 0.00001 \\
$\alpha_{3}\left(\mathrm{~s}^{-1}\right)$ & $3.0 \times 10^{3}$ & $3.0 \times 10^{3}$ \\
$\beta_{3}\left(\mathrm{~s}^{-1}\right)$ & $1.0 \times 10^{3}$ & $1.0 \times 10^{3}$ \\
$10-90 \%$ rise time (msec) & 0.28 & 2.3 \\
$\tau_{\text {decay }}(\mathrm{msec})$ & 3.0 & 133.0 \\
$P_{0, \text { max }}$ & 0.60 & 0.29 \\
$\gamma(\mathrm{ps})$ & 16 & 6 \\
\hline & &
\end{tabular}

mEPSCs evoked in the presence of $\mathrm{Sr}^{2+}$ were visually detected and aligned by point of initial rise for averaging. For the slow mEPSCs, two investigators independently identified mEPSCs with good agreement, as described previously (Kidd and Isaac, 1999). Only events that initiated within $700 \mathrm{~ms}$ of the stimulus were used. The frequency of non-evoked spontaneous EPSCs in layer IV neurons at this developmental stage is $\sim 0.1 \mathrm{~Hz}(0.11 \pm 0.02 \mathrm{~Hz} ; n=22)$; thus, the probability of contamination of the evoked mEPSCs by a non-evoked spontaneous event is very low. Exponential fitting of EPSC decay was performed using SigmaPlot (Systat Software, Point Richmond, CA) as described previously (Kidd and Isaac, 1999). Charge transfer for each component was calculated as the product of the peak amplitude (at $t=0$ ) and the decay time constant. Quantal content $(m)$ for the dual-component EPSCs was estimated for each component by dividing the peak amplitude (estimated as the amplitude of the component at $t=0$ from the exponential fit) by the quantal amplitude determined from the evoked mEPSCs. Nonstationary fluctuation analysis (NSFA) of synaptic currents (Robinson et al., 1991; Traynelis et al., 1993) was performed as described previously (Benke et al., 1998; Lüthi et al., 1999; Benke et al., 2001; Lüthi et al., 2004). Briefly, EPSCs were aligned by their point of maximal rise and averaged. The average response waveform was scaled to the peak of individual responses, and the variance of the fluctuation of the decays around the mean was calculated. This variance was binned (10-100 bins of equal current decrement), and the single-channel current was then estimated by fitting the data to the following: $\sigma^{2}=i I-I^{2} / N+b_{1}$, where $\sigma^{2}$ is the variance, $I$ is the mean current, $N$ is the number of channels activated at the peak, $i$ is the single-channel current, and $b_{1}$ is the background variance (Sigworth, 1980). The single-channel conductance $(\gamma)$ is then $\gamma=i / V$, where $V$ is the driving force (holding potential - assumed reversal potential of $0 \mathrm{mV}$ ). Pooled data are represented as mean \pm SEM. Statistical analysis was performed using the Student's $t$ test, and $p<0.05$ was considered significant.

\section{Results}

Extracellular $\mathrm{Sr}^{2+}$ allows the study of quantal transmission at developing thalamocortical synapses

To study neonatal thalamocortical synapses, we made whole-cell voltage-clamp recordings from layer IV neurons in mouse barrel cortex prepared from pups aged between postnatal days 2 and 9 (Fig. 1A-C). Stimulation of thalamocortical axons, in the presence of the NMDA receptor antagonist D-AP-5 $(50 \mu \mathrm{M})$ and the $\mathrm{GABA}_{\mathrm{A}}$ receptor antagonist PTX $(100 \mu \mathrm{M})$ typically evokes a dual-component EPSC in neonatal layer IV neurons (Figs. $1 D$, $2 A$ ). Previously, we have shown that this dual-component EPSC 

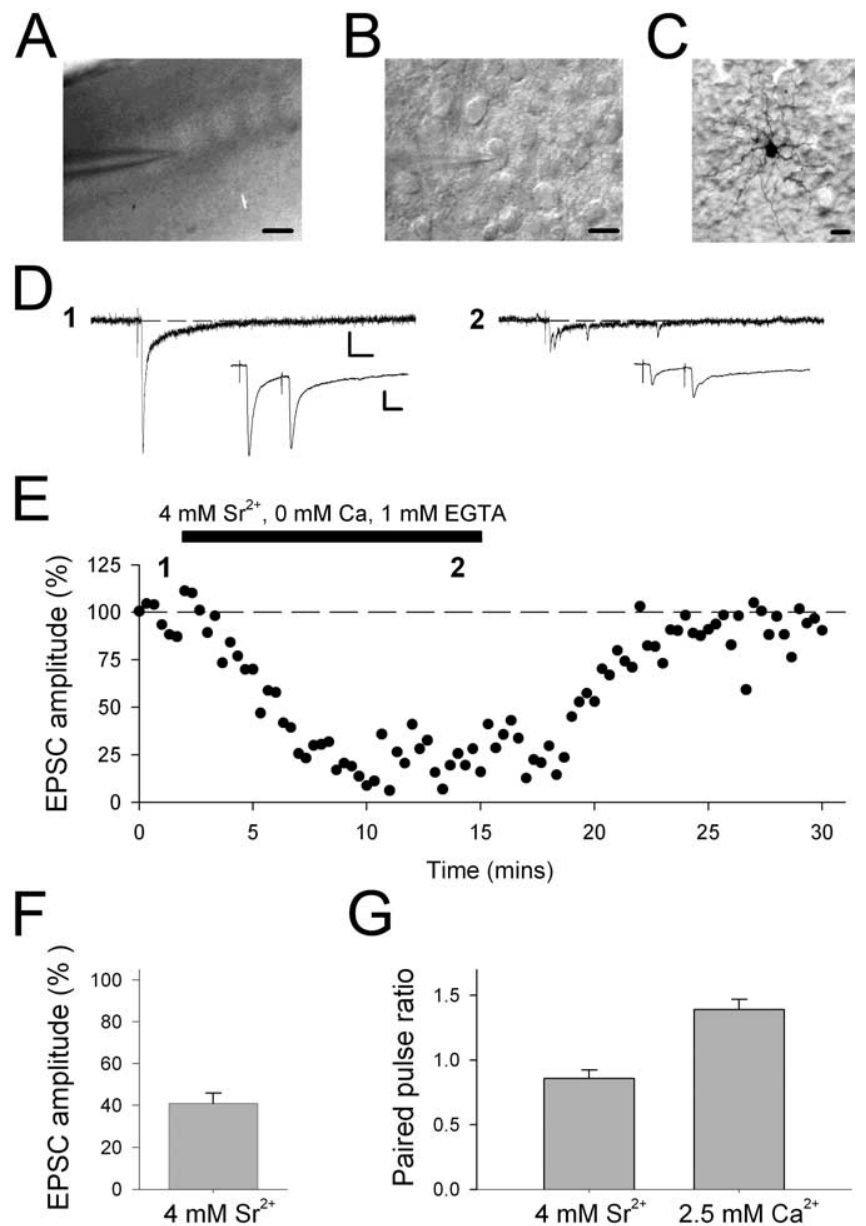

Time (mins)

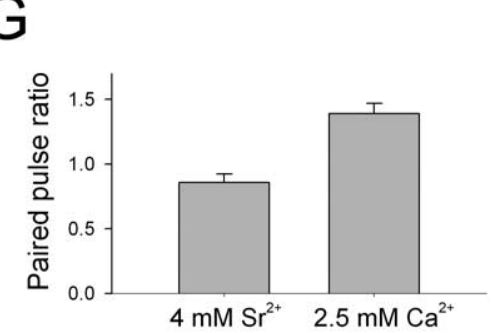

Figure 1. Extracellular $\mathrm{Sr}^{2+}$ desynchronizes release at thalamocortical synapses in developing barrel cortex. $A$, Low-power infrared DIC image of the barrel cortex in a thalamocortical slice in the recording chamber. Scale bar, $100 \mu \mathrm{m}$. B, High-power infrared DIC image of a neuron in barrel cortex during a patch-clamp recording. Scale bar, $10 \mu \mathrm{m}$. C, Biocytin-filled cell in layer IV neonatal barrel cortex. Scale bar, $10 \mu \mathrm{m}$. For $\boldsymbol{A}-\boldsymbol{C}$, pial surface is located toward the top. D, Example EPSCs (single traces) evoked by stimulation in ventrobasal thalamus collected during a whole-cell patch-clamp recording from a layer IV neuron in the barrel cortex in the presence of normal extracellular solution $\left(2.5 \mathrm{~mm} \mathrm{Ca}^{2+}, 0 \mathrm{~mm} \mathrm{Sr}{ }^{2+}\right.$; left) and in the presence of $4 \mathrm{~mm} \mathrm{Sr}^{2+}$ (2 $\mathrm{mm}$ EGTA, $0 \mathrm{~mm} \mathrm{Ca}^{2+}$; right). Insets show averaged EPSCs from the same cell evoked by paired-pulse stimulation. $\boldsymbol{E}$, Example experiment (same cell as in $\boldsymbol{D}$ ) showing EPSC amplitude (percentage of baseline before application of $\mathrm{Sr}^{2+}$ ) versus time for an experiment in which $4 \mathrm{~mm} \mathrm{Sr}{ }^{2+}\left(2 \mathrm{~mm}\right.$ EGTA, $\left.0 \mathrm{~mm} \mathrm{Ca}{ }^{2+}\right)$ was applied extracellularly. $\boldsymbol{F}$, Summary data from 14 cells showing the reduction in EPSC amplitude with $\mathrm{Sr}^{2+}$ application. G, Summary data from eight cells showing the change in paired-pulse ratio $\left(\mathrm{EPSC}_{2} / \mathrm{EPSC}_{1}\right)$ with $\mathrm{Sr}^{2+}$.

is composed of a fast AMPA receptor-mediated component and a slow kainate receptor-mediated component (Kidd and Isaac, 1999, 2001). To investigate the quantal properties of kainate and AMPA receptor-mediated transmission underlying these dualcomponent evoked EPSCs, we used extracellular $\mathrm{Sr}^{2+}$, which desynchronizes release at central synapses (Goda and Stevens, 1994). When extracellular $\mathrm{Ca}^{2+}$ is replaced by $\mathrm{Sr}^{2+}$, extracellular stimulation can be used to evoke both a synchronous EPSC as well as a barrage of mEPSCs, which occur for up to $1 \mathrm{~s}$ after the synchronous event. In this way, mEPSCs are evoked that originate from the stimulated input, thus allowing quantal properties of transmission to be investigated at identified inputs (Goda and Stevens, 1994; Abdul-Ghani et al., 1996; Oliet et al., 1996; Gil et al., 1999; Xu-Friedman and Regehr, 2000; Lu et al., 2003).

We first collected evoked EPSCs in normal extracellular me-
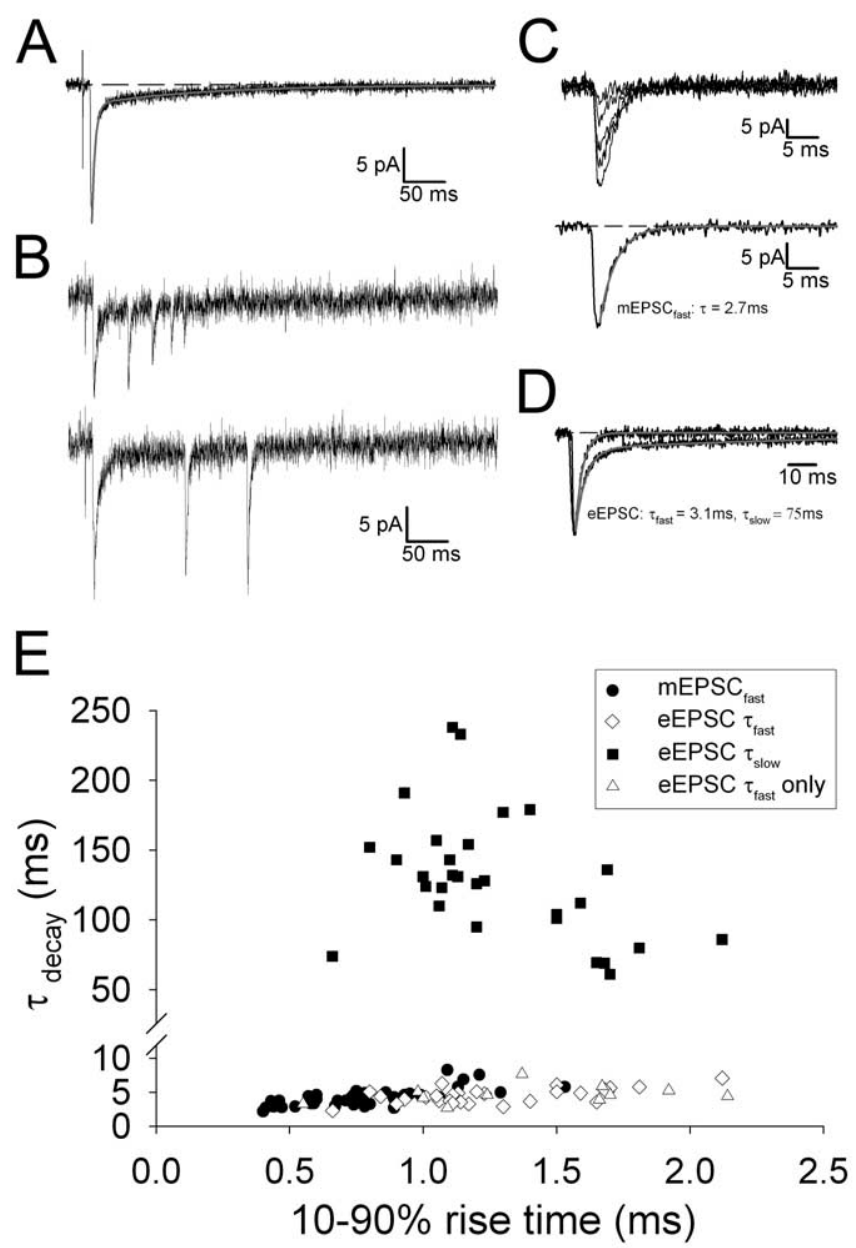

Figure 2. Fast-rising mEPSCs at thalamocortical synapses are mediated by a single component, whereas evoked EPSCs at the same input are dual component. $A$, Example averaged eEPSC (in $2.5 \mathrm{~mm} \mathrm{Ca}{ }^{2+}, 0 \mathrm{~mm} \mathrm{Sr}{ }^{2+}$ ) and double-exponential fit to the decay (gray). All data in $A-D$ are from the same cell. $\boldsymbol{B}$, Examples of two traces (not averaged) in the presence of $\mathrm{Sr}^{2+}(0 \mathrm{~mm}$ $\mathrm{Ca}^{2+}, 2 \mathrm{~mm}$ EGTA) showing the synchronized eEPSC followed by evoked mEPSC $\mathrm{fast}_{\text {. }}$, Aligned and superimposed $\mathrm{mEPSC}_{\text {fast }}$ events (top) and average of these (bottom). The gray line is a single-exponential fit to the decay. $\boldsymbol{D}$, Averaged $\mathrm{mEPS}_{\text {fast }}$ (same trace as in $\boldsymbol{C}$ ) and averaged eEPSC (same trace as in $\boldsymbol{A}$ ) from the same cell aligned, peak scaled, and superimposed. The gray lines are single (for EPSC $_{\text {fast }}$ ) and double (for eEPSC) exponential fits to the decay. $\boldsymbol{E}$, Summary data of $\tau_{\text {decay }}$ plotted versus $10-90 \%$ rise time for mEPSC $_{\text {fast }}$ (filled circles; $n=42$ ), for dualcomponent eEPSCs (open diamonds, fast $\tau_{\text {decay }}$; filled squares, slow $\tau_{\text {decayi }} ;=29$ ), and for eEPSC with only a fast component (open triangles; $n=13$ ).

dium (containing $2.5 \mathrm{mM} \mathrm{Ca}^{2+}$ ) and then replaced this with a medium containing $4 \mathrm{mM} \mathrm{Sr}^{2+}, 2 \mathrm{mM}$ EGTA, and $0 \mathrm{mM} \mathrm{Ca}^{2+}$. The exchange of $\mathrm{Ca}^{2+}$ with $\mathrm{Sr}^{2+}$ caused a reduction in synchronized eEPSC amplitude and produced desynchronized mEPSCs that were highly correlated with the stimulus (Fig. $1 D, E$ ), similar to that reported previously for thalamocortical synapses (Gil et al., 1999; Lu et al., 2003). The peak eEPSC was reduced to $41 \pm$ $5 \%$ of baseline $(n=14)$ (Fig. $1 F)$, and this was associated with an increase in the paired-pulse ratio (from $0.86 \pm 0.07$ to $1.39 \pm$ $0.07 ; n=8 ; p<0.01$ ) (Fig. $1 D, G$ ), indicating that $\mathrm{Sr}^{2+}$ caused a reduction in release probability of eEPSC. In some experiments, 8 $\mathrm{mM} \mathrm{Sr}{ }^{2+}$ and 2 mM EGTA was used. This was more effective in supporting synchronous evoked release and produced a higher frequency of evoked mEPSCs. This initial characterization therefore confirmed that extracellular $\mathrm{Sr}^{2+}$ can be used to evoked mEPSCs at thalamocortical synapses in developing barrel cortex. 
Quantal properties of AMPA and kainate receptor-mediated synaptic transmission

Because $\mathrm{Sr}^{2+}$-evoked mEPSCs are produced by quantal release evoked at single synapses (Goda and Stevens, 1994; Gil et al., 1999), this technique can be used for studying the quantal properties of developing thalamocortical synapses (Gil et al., 1999; Lu et al., 2003). We therefore characterized the mEPSCs evoked in the presence of $\mathrm{Sr}^{2+}$. Fast rising mEPSCs were evoked in all cells $(10-90 \%$ rise time, $0.78 \pm 0.04 \mathrm{~ms} ; n=42)$ (Fig. 2$)$ and had a mean amplitude of $10.6 \pm 0.5 \mathrm{pA}(n=42)$. This is very similar to previous estimates of the quantal amplitude of AMPARmediated EPSCs for the thalamocortical input in barrel cortex using minimal stimulation (Isaac et al., 1997; Gil et al., 1999; Kidd and Isaac, 1999) or $\mathrm{Sr}^{2+}$-evoked mEPSCs (Gil et al., 1999; Lu et al., 2003). A single exponential always provided a good fit of the decay of $\mathrm{mEPSC}_{\text {fast }}\left(\tau_{\text {decay }}=4.2 \pm 0.2 \mathrm{~ms} ; n=42\right)$. The kinetics of these events is very similar to our previous reports of the kinetics of AMPA receptor-mediated transmission at this input (Kidd and Isaac, 1999, 2001). For each cell, the kinetics of the eEPSC before $\mathrm{Sr}^{2+}$ application were also measured. In the majority of cells (29 of 42), the decay of the eEPSC was well fit with two exponentials $\left(\tau_{\text {fast }}=4.5 \pm 0.2 \mathrm{~ms} ; \tau_{\text {slow }}=127.8 \pm 8.5 \mathrm{~ms}\right.$; fast component amplitude, $50.5 \pm 7.3 \mathrm{pA}$; slow component amplitude, $8.3 \pm 1.4 \mathrm{pA} ; n=29$ ) (Fig. 2). The time course of the slow component of these dual-component eEPSCs is very similar to that reported previously for the kainate receptor-mediated component of transmission at this input (Kidd and Isaac, 1999, 2001). eEPSCs from the remaining cells decayed with a single fast exponential. Together, these data show that, although evoked compound thalamocortical EPSCs are typically mediated by both AMPA and kainate receptors, EPSC $_{\text {fast }}$ evoked at the same inputs are always mediated solely by AMPA receptors.

One possibility to explain this observation is that kainate receptors are extrasynaptic and are not activated by a single quantum of released glutamate. Indeed, this has been proposed previously to explain the slow kinetics of kainate receptor-mediated synaptic currents (Castillo et al., 1997; Vignes and Collingridge, 1997; Min et al., 1998; Lerma et al., 2001). Another possibility, however, is that kainate receptors do participate in quantal transmission but that they are not coactivated with AMPA receptors. This latter possibility predicts that a second population of slow kainate receptor-mediated quantal events should be observed in the presence of $\mathrm{Sr}^{2+}$. As shown in Figure 3, such events could indeed be detected. Slow mEPSCs evoked in the presence of $\mathrm{Sr}^{2+}$ (Fig. $3 B, C$ ) coexisted at the same population of inputs with $\mathrm{mEPSC}_{\text {fast }}$ (Fig. $\left.3 D, E\right) \cdot \mathrm{mEPSC}_{\text {slow }}$ had a slow rise time $(4.1 \pm 0.3$ $\mathrm{ms} ; n=10)$ and decayed with a single slow exponential $\left(\tau_{\text {decay }}=\right.$ $133 \pm 9 \mathrm{~ms} ; n=6)$ (Fig. $3 C$ ), very similar to the slow component of the decay of dual-component eEPSCs $\left(\tau_{\text {decay }}=127.8 \pm 8.5 \mathrm{~ms}\right.$; $n=29$ ) (Fig. $3 G, H$ ) and to previous estimates of the kainate receptor-mediated component of transmission (Kidd and Isaac, 1999, 2001). In a subset of cells, we could evoke a slow kainate receptor-mediated eEPSC $\left(\right.$ eEPSC $_{\text {slow }}$ ) in the absence of a fast component (Fig. $3 F$ ). As described previously, these events represent kainate receptor-mediated eEPSCs, which can be evoked preferentially in younger animals with minimal stimulation attributable to selective activation of axons making "kainate-only" synapses onto the recorded cell (Kidd and Isaac, 1999). The rise

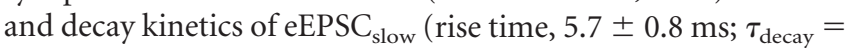
$134.1 \pm 9.5 \mathrm{~ms} ; n=9$ ) were very similar to those of mEPSC $_{\text {slow }}$ (Fig. $3 G, H$ ). These data show that kainate receptors can be activated by a single quantum of released transmitter. Moreover, it demonstrates that AMPA and kainate receptor-mediated quantal
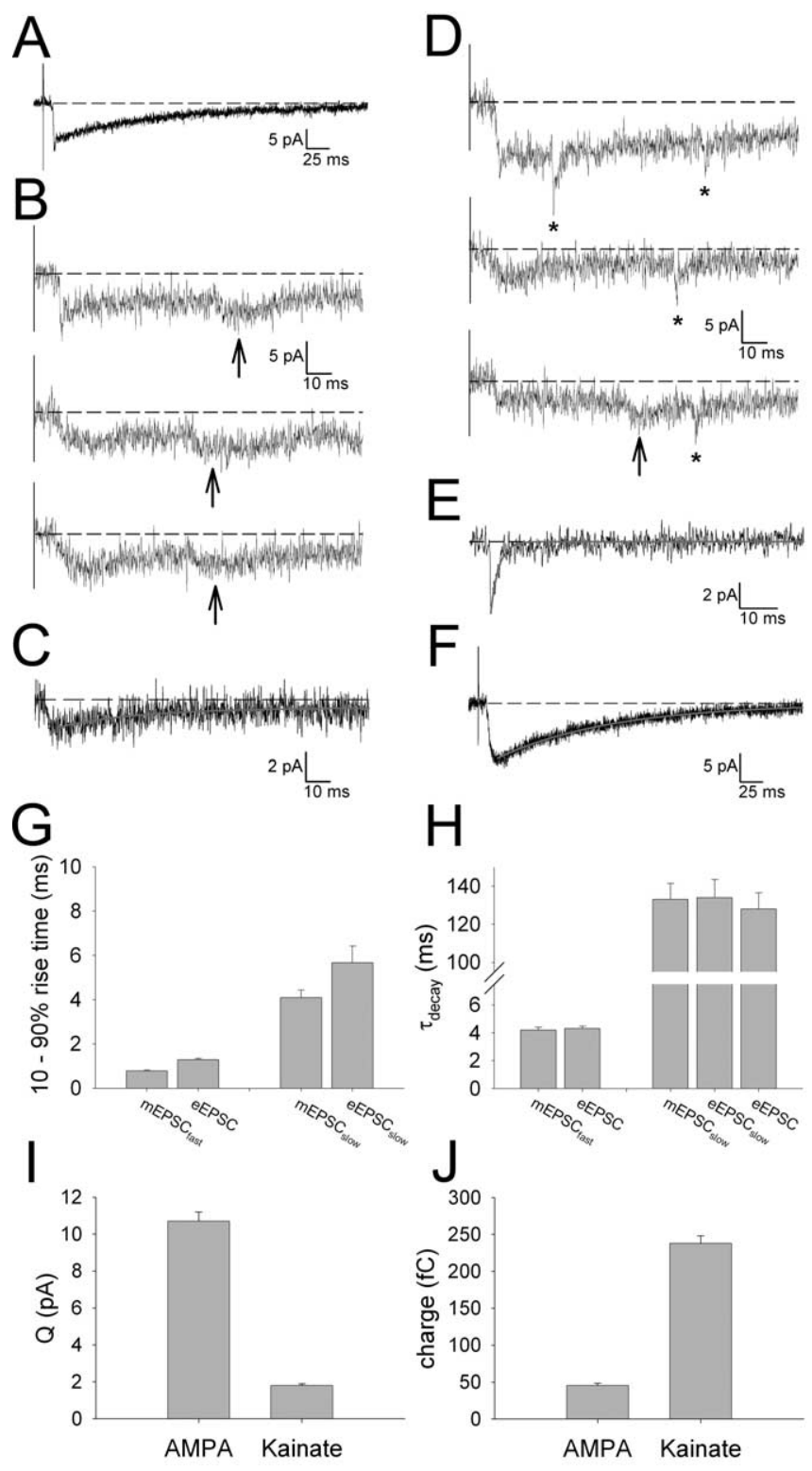

Figure 3. Kainate receptors mediate quantal events independently from AMPA receptors at the same population of inputs onto the same cells. $A$, Example averaged eEPSC (in $2.5 \mathrm{mu} \mathrm{Ca}^{2+}$, $\left.0 \mathrm{~mm} \mathrm{Sr}^{2+}\right)$. Data in $\boldsymbol{A}-\boldsymbol{E}$ are from the same cell. $\boldsymbol{B}$, Example individual traces in the presence of $\mathrm{Sr}^{2+}\left(0 \mathrm{~mm} \mathrm{Ca}^{2+}, 2 \mathrm{~mm}\right.$ EGTA) showing the eEPSC followed by evoked $\mathrm{mEPSC}_{\text {slow }}$ (indicated by arrows). C, Averaged $\mathrm{mEPSC}_{\text {slow }}$ and single-exponential fit of the decay (gray). D, Example individual traces in the presence of $\mathrm{Sr}^{2+}\left(0 \mathrm{~mm} \mathrm{Ca}{ }^{2+}, 2 \mathrm{~mm}\right.$ EGTA) showing the eEPSC followed by evoked $m E P S C_{\text {fast }}$ (indicated by asterisks; note that both $m E P S C_{\text {fast }}$ and $m E P S C_{\text {slow }}$ events are evident in the bottom trace). $\boldsymbol{E}$, Averaged $\mathrm{mEPSC}_{\text {fast }}$ and single-exponential fit to the decay (gray). $\boldsymbol{F}$, Averaged eEPSC $C_{\text {slow }}$ and single-exponential fit to the decay (gray). $\boldsymbol{G}$, Values for $10-$ $90 \%$ rise time: left, $\mathrm{mEPSC}_{\text {fast }}(n=42)$, eEPSC $(n=42)$; and right, $\mathrm{mEPSC}_{\text {slow }}(n=10)$ and eEPSC $_{\text {slow }}(n=10) . \boldsymbol{H}, \tau_{\text {decay }}$ values: left, $\mathrm{mEPSC}_{\text {fast }}(n=42)$ and the fast component of eEPSC $(n=42)$; right, $\mathrm{mEPSC}_{\text {slow }}(n=6), \mathrm{eEPSC}_{\text {slow }}(n=9)$, and the slow component of eEPSC $(n=$ 29). I, Summary data of the mean quantal amplitude ( $Q)$ of AMPA $(n=42)$ and kainate $(n=$ 13) receptor-mediated evoked $m E S P C S$.J, Summary data for the mean charge carried by the two types of evoked mEPSCS (AMPA, $n=42$; kainate, $n=6$ ).

events are evoked independently at the same population of thalamocortical synapses onto the same layer IV cell. This is consistent with our previous findings showing that minimal stimulation can independently evoke the two types of events (Kidd and Isaac, 1999) and strongly suggests that, at developing thalamo- 
cortical inputs, AMPA and kainate receptors are not colocalized at the same synapses.

The detection of evoked mEPSC $_{\text {slow }}$ in addition to mEPSC $_{\text {fast }}$ allowed us to compare the quantal properties of both AMPA and kainate receptor-mediated transmission. The mean peak amplitude of the evoked mEPSCs provided an estimate for quantal amplitude ( $Q)$. $Q$ for AMPA receptor-mediated transmission $\left(Q_{\text {AMPA }}\right)$ was $10.7 \pm 0.5 \mathrm{pA}(n=42)$ (Fig. $3 I)$, very similar to that reported previously for AMPA receptor-mediated mEPSCs at thalamocortical synapses in barrel cortex (Gil et al., 1999; Lu et al., 2003). $Q_{\text {kainate }}$ was approximately one-sixth of that for AMPA receptor-mediated transmission $\left(Q_{\text {kainate }}=1.8 \pm 0.1 \mathrm{pA} ; n=13\right)$ (Fig. $\left.3 I\right)$; however, the quantal charge transfer for kainate receptors was approximately fivefold greater than that for AMPA receptors (charge kainate, $237.5 \pm 10.4 \mathrm{fC}, n=6$; charge AMPA, $45.4 \pm 2.9 \mathrm{fC}, n=42$ ) (Fig. $3 J)$. These differences in the quantal size, charge transfer, and kinetics indicate that these two types of synapse have very different effects on the postsynaptic cell (Frerking and Ohliger-Frerking, 2002).

It was notable that mEPSC $_{\text {slow }}$ were only readily detected in a subset of neurons. This could be attributable to the slow kinetics and small peak amplitude of these events making it only possible to reliably detect them above noise in a subset of cells. Alternatively, it is possible that kainate receptors only participate in quantal transmission at a subset of inputs and that a considerable fraction of the kainate receptor-mediated component of eEPSC is attributable to the activation of extrasynaptic receptors. To test this idea, we investigated the effects of TBOA [DL-threo- $\beta$ benzyloxyaspartic acid], which blocks high-affinity glutamate transporters (Shimamoto et al., 1998; Jabaudon et al., 1999). This manipulation has been used to show that glutamate transporters limit glutamate diffusion at synapses onto retinal ganglion neurons and prevent quantal activation of NMDA receptors that are exclusively located extrasynaptically (Chen and Diamond, 2002). We therefore compared the kinetics of evoked mEPSC $_{\text {fast }}$ in the presence of $\mathrm{Sr}^{2+}$ and in the presence of $\mathrm{Sr}^{2+}$ plus TBOA $(20 \mu \mathrm{M})$ (Fig. 4). TBOA had no effect on the rise or decay kinetics of mEPSC $_{\text {fast }}$ or on peak amplitude. Furthermore, in the presence of TBOA, no slow component to the evoked mEPSC was revealed. However, as a positive control, in separate interleaved experiments, we found that TBOA caused a reversible depression of eEPSC peak amplitude (EPSC amplitude percentage baseline: TBOA, $45 \pm 6 \%$; wash, $85 \pm 2 \% ; n=5)$. This effect is very similar to that observed in our previous work using glutamate transport inhibitors (Kidd and Isaac, 2000, 2001) and demonstrates that TBOA was effective in blocking glutamate transport in the present experiments. Thus, the lack of effect of TBOA on mEPSC $_{\text {fast }}$ decay suggests that the reason mEPSC $_{\text {slow }}$ were not detected in some neurons is not attributable to an extrasynaptic location of kainate receptors. Rather, it suggests that $\mathrm{mEPSC}_{\text {slow }}$ were falling below the threshold for reliable detection in some neurons because of their small amplitudes and slow kinetics.

\section{Analysis of the properties of AMPA and kainate receptors using the voltage-jump technique}

The AMPA and kainate receptor-mediated miniature events exhibit strikingly different kinetics and amplitudes. Kainate receptor-mediated EPSCs have been characterized for a number of inputs in the mammalian CNS and, in the great majority of cases, exhibit slow kinetics when compared with AMPARmediated synaptic currents (Lerma et al., 2001). However, the reason for the slow kinetics is unclear. One possibility is that kainate receptors exhibit rapid AMPAR-like kinetics but are found at synapses so remote from the soma that, when using somatic patch-clamp recordings, a heavily filtered current is observed. We tested this idea using the voltage-jump technique, which enables an estimation of the true time course of synaptic conductance to be obtained using somatic whole-cell patchclamp recordings (Pearce, 1993; Häusser and Roth, 1997; Walker et al., 2002). Dual-component eEPSCs were evoked at a membrane potential of $-60 \mathrm{mV}$ and voltage jumps to $-90 \mathrm{mV}$ applied with short interval during the fast AMPA receptor-mediated component and at a longer interval during the slow kainate receptor-mediated component (Fig. 5A). The membrane capacitance artifacts were removed using interleaved voltage jumps in the absence of synaptic currents. The onset and duration of charge recovery enabled both the electrotonic location and the true time course of the AMPA receptor-mediated synaptic conductance to be estimated (Pearce, 1993; Häusser and Roth, 1997; Walker et al., 2002) (Fig. 5 B, C). Our estimate for the duration of the synaptic conductance for AMPARs agreed well with the other studies (Häusser and Roth, 1997; Walker et al., 2002), and the electrotonic index obtained suggested, on average, a relatively proximal location for the synapses. Our voltage-jump experiments also allowed us to investigate the time course of the synaptic conductance of kainate receptors. Strikingly, we observed charge recovery for the kainate receptor-mediated EPSC up to at least $100 \mathrm{~ms}$ after EPSC onset (Fig. 5D,E). Because the kainate receptor-mediated component of the EPSC is small in amplitude, the signal-to-noise ratio was too low to reliably quantify the time 
A
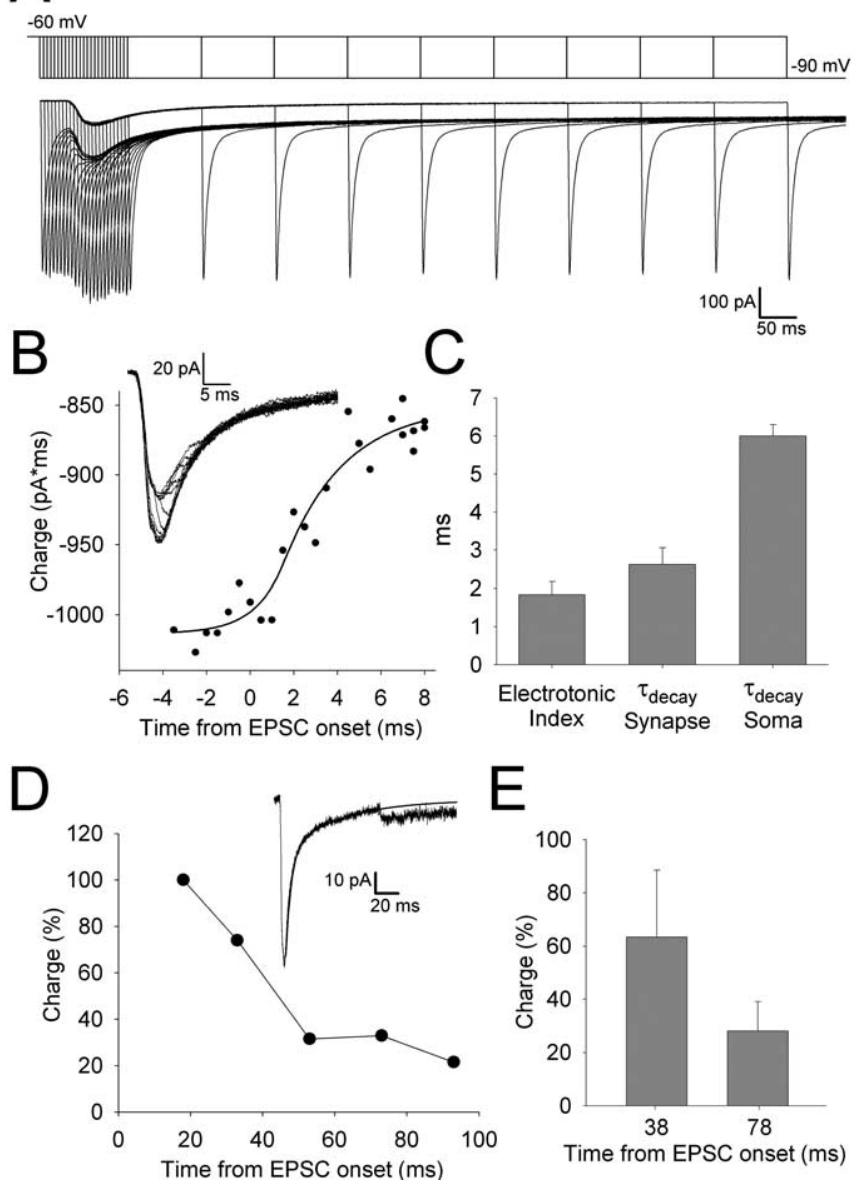

Figure 5. Voltage-jump analysis reveals that channels with slow kinetics underlie the kainate receptor-mediated EPSC. $\boldsymbol{A}$, Superimposed currents (bottom) recorded from a cell in response to the superimposed voltage-jump protocol (top). For each trace, a single jump from -60 to $-90 \mathrm{mV}$ was applied during the AMPA or kainate receptor-mediated component of the EPSC. $\boldsymbol{B}$, Charge recovery curve for the fast AMPAR-mediated component to the EPSC. The line is a sigmoidal fit to the data (see Materials and Methods). Inset, Superimposed traces showing the early fast component of the EPSC after subtraction of the capacitance transients illustrating the charge recovery during the AMPAR-mediated EPSC. C, Summary data from all cells $(n=5)$ for electrotonic index and $\tau_{\text {decay }}$ of the synaptic conductance (both derived from the sigmoidal fit to the charge recovery data as in $\boldsymbol{B}$ ) and $\tau_{\text {decay }}$ of the AMPAR-mediated EPSC $C_{\text {fast }}$ as recorded at the soma. $\boldsymbol{D}$, Charge recovery during the kainate receptor-mediated component of the EPSC for an example cell (charge recovery estimated as the difference between the peak amplitude of the recovered current relative to the slow exponential decay of the kainate receptor-mediated component and normalized to charge recovered at $18 \mathrm{~ms}$ ). Inset, Example EPSC (capacitance transient subtracted) showing charge recovery for the slow kainate receptor-mediated component at $78 \mathrm{~ms}$ after EPSC onset. The line is a biexponential fit to the decay of the EPSC. $\boldsymbol{E}$, Charge recovery (normalized to recovery at $18 \mathrm{~ms}$ ) for the kainate receptor-mediated component at 38 and $78 \mathrm{~ms}$ after EPSC onset for all cells in which this analysis could be performed $(n=4)$.

course of the synaptic conductance or the electrotonic index. Nevertheless, our data clearly show that the channels mediating the slow kainate receptor EPSC are open for at least $100 \mathrm{~ms}$.

\section{Modeling suggests that small conductance channels with slow} kinetics underlie the kainate receptor-mediated EPSC

The findings from the voltage-jump experiments indicate that differences in the electrotonic location of AMPA and kainate synapses are unlikely to significantly contribute to the differences in the kinetics and amplitude of the AMPA and kainate receptormediated EPSCs. To further address this issue, we made a compartmental model of a neonatal layer IV stellate neuron using morphological and electrophysiological measurements made from neonatal stellate cells in our preparation (Fig. 1C) and morphological data from a previous stellate cell model (Bannister et al., 2002). We used an approach that we applied to other cell types (Benke et al., 1998, 2001) in which a kinetic scheme for the channels underlying the synaptic conductance generates a current at the synapse and the resulting simulated EPSCs are recorded by a simulated whole-cell patch electrode in voltage clamp (Fig. 6A). A genetic algorithm (Youngs, 2002; Taylor and Enoka, 2004) was used to explore parameter space for the various electrical and morphological parameters, and goodness of fit was judged by comparing membrane responses to voltage steps between real experiments and the model (see Materials and Methods and Table 1). This enabled us to generate a model neuron that produces AMPAR-mediated EPSCs very similar to the experimentally recorded currents when an AMPAR kinetic scheme (Diamond and Jahr, 1997) was used (Fig. 6A, B; Table 3).

We used the model to investigate the possibility that the slow kainate receptor-mediated EPSC we observe is mediated by fast AMPAR-like channels that are heavily filtered by the dendritic tree. Using the genetic algorithmic approach, we attempted to generate a model neuron that could produce slow EPSCs recorded at the soma although the synaptic currents had fast AMPAR-like kinetics. When the geometry was constrained by what was realistic (Fig. 1C), the genetic algorithm was unable to find a set of parameters that turned a fast synaptic current into a slow one (Fig. 6C,D; Table 2). When the geometry was not constrained, this produced an extreme model in which slow EPSCs were observed (Fig. 6C,D). However, the model was very unrealistic in that membrane parameters outside the normal range had to be used and the neuron was seven times larger than the real size of these neurons at this developmental stage (Table 2; Fig. 6C,D). This analysis, in addition to the voltage-jump data, indicates that it is very unlikely that the slow kinetics of the kainate receptormediated EPSC are attributable to heavy electrotonic filtering of underlying channels with fast AMPA receptor-like kinetics.

We also used the model to investigate whether $\gamma$ of AMPA and kainate receptors underlying the fast and slow components to transmission, respectively, could be estimated using NSFA (Robinson et al., 1991; Traynelis et al., 1993). We used this approach previously and have shown that NSFA can be used to obtain estimates for $\gamma$ of AMPAR channels mediating EPSCs in CA1 pyramidal neurons when using dendritic whole-cell recordings (Benke et al., 1998, 2001). Estimates of $\gamma$ of AMPARs underlying EPSCs originating from synapses at different electrotonic locations were obtained using NSFA (Fig. $6 E-G$ ). Increasing attenuation in estimated $\gamma$ was observed as electrotonic distance increased. As an initial estimate, we used the electrotonic index from voltage-jump experiments coupled with the compartmental model (Häusser and Roth, 1997), which indicated that AMPA synapses must be $<40 \mu \mathrm{m}$ from the soma. To refine this estimate, we also measured the $10-90 \%$ rise time of these simulated AMPAR-mediated EPSCs and found that this parameter increased with electrotonic distance, as expected. By comparing this relationship with the mean $10-90 \%$ rise time for the experimentally recorded AMPAR-mediated mEPSCs, we estimated that, on average, the synapses from which the synaptic currents originated were $\sim 22 \mu \mathrm{m}$ from the soma. The model predicts that $\gamma$ estimated from AMPARs from synapses at this location is attenuated to $55 \%$ of the true value.

We used a modified AMPAR kinetic scheme to simulate kainate receptors with slow kinetics and low single-channel conductance (see Materials and Methods and Table 3). The kinetic pa- 
rameters of kainate receptors, when placed at a similar electrotonic location of AMPA receptors, were adjusted to give synaptic waveforms that were similar to experimental data (Fig. 6H). Using these simulated kainate receptor-mediated EPSCs, we first investigated whether they show linear summation. We found that, like AMPAR-mediated EPSCs, kainate receptor-mediated EPSCs sum linearly; both simulated AMPA and kainate receptor-mediated EPSCs from synapses 15-77 $\mu \mathrm{m}$ from the soma summed with better than 95\% linearity. We next investigated the degree of attenuation of $\gamma$ when using NSFA of the simulated kainate receptor channels. Attenuation in the estimate of $\gamma$ as a function of electrotonic distance for the kainate receptor channels was less steep than for AMPAR channels (Fig. $6 I-K)$. Using the experimentally determined rise time of the kainate receptormediated mEPSCs, we estimated that the synapses from which these currents originate were, on average, $\sim 15 \mu \mathrm{m}$ from the soma, a similar location to that predicted for the AMPA synapses. Based on the model, the $\gamma$ estimate for the kainate receptor channels at these synapses is attenuated to $58 \%$ of the true value. Thus, the modeling indicates that estimates for $\gamma$ of AMPAR and kainate receptor channels can be obtained using NSFA from neonatal layer IV cells and that the amount of attenuation of estimate for $\gamma$ is similar for both receptor types.

\section{Single-channel properties of synaptic AMPA and kainate receptors}

To investigate the single-channel properties of the AMPA receptors mediating quantal synaptic transmission, we performed NSFA (Robinson et al., 1991; Traynelis et al., 1993; Benke et al., 1998, 2001; Lüthi et al., 1999, 2004) on experimentally recorded $\mathrm{mEPSC}_{\text {fast }}$ to obtain estimates for AMPA receptor $\gamma$. Examples for this from two cells are shown in Figure 7 [one cell exhibiting a large $\gamma$ value $(A-C)$ and one with a low $\gamma$ value $(D-F)]$. For each individual cell, the value for $\gamma$ obtained represents a weighted average from all AMPAR channels contributing to all of the mEPSC $_{\text {fast }}$ used for the analysis. Thus, the value of $\gamma$ for each cell reflects both intrasynaptic and intersynaptic variability and is influenced by the number and relative open time of each different channel present. Across cells, we observed a wide range of $\gamma$ values, and the frequency histogram was suggestive of a bimodal distribution (Fig. $7 G$ ). The range of values corresponded well with the previously reported range of $\gamma$ for AMPA receptors (Traynelis et al., 1993; Spruston et al., 1995; Silver et al.,
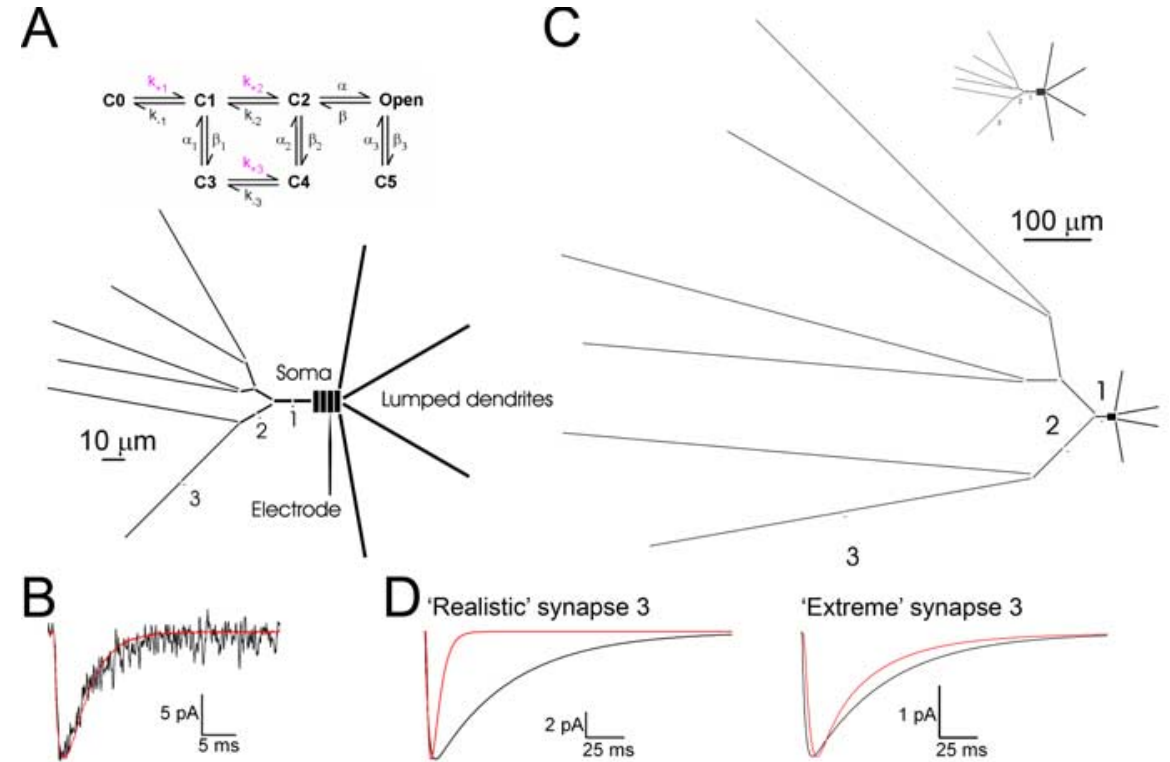

D'Realistic' synapse 3

3
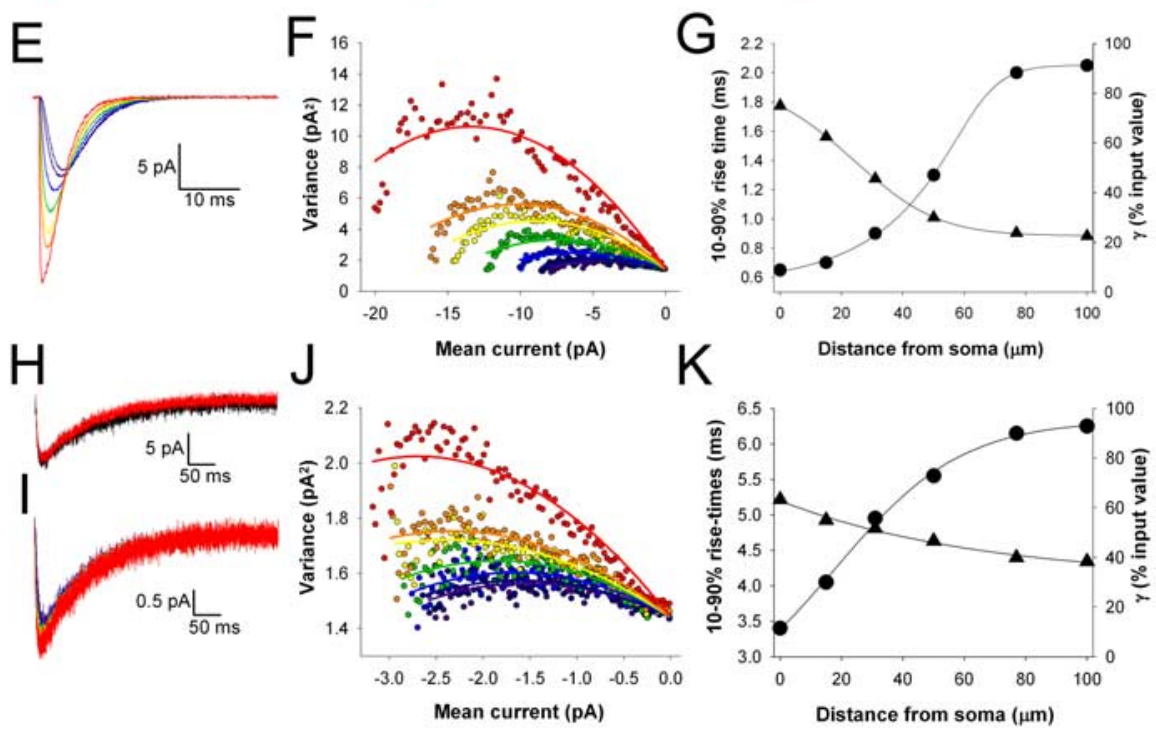

Figure 6. Modeling indicates that low-conductance channels with slow kinetics underlie the kainate receptor-mediated EPSC. $A$, Diagram of the model neuron with one explicitly modeled dendrite and four lumped dendrites. A patch electrode located on the soma is indicated, as is the position of three synapses at different electrotonic locations. Inset at top, Kinetic scheme used for the channels underlying the synaptic conductance. $\boldsymbol{B}$, AMPAR-mediated simulated mean EPSC (red) from synapse 1 (at $15 \mu \mathrm{m}$ from soma) generated by the realistic model and superimposed on an experimentally recorded evoked AMPAR-mediated mEPSC.C, The extreme model neuron that was generated to produce slow simulated EPSCs from fast AMPAR-like currents applied at synapse 3 . Inset at top, Realistic model shown at the same scale for comparison. D, Simulated EPSC (red) generated by a fast AMPAR-like EPSC injected at synapse 3 superimposed on the slow kainate receptor-like simulated EPSC (black) for the realistic model (left) and extreme model (right). $\boldsymbol{E}$, Superimposed simulated AMPAR-mediated EPSCs when recorded using the simulated patch electrode from the realistic model from synapses located at $0 \mu \mathrm{m}$ (orange), $15 \mu \mathrm{m}$ (yellow), $31 \mu \mathrm{m}$ (green), $50 \mu \mathrm{m}$ (blue), $77 \mu \mathrm{m}$ (dark blue), and $100 \mu \mathrm{m}$ (purple) from the soma. The EPSC at the soma not filtered by the recording electrode from a synapse located at $0 \mu \mathrm{m}$ (perfectly clamped; red) is also shown for comparison. $\boldsymbol{F}$, Binned squared difference current (variance) plotted versus current amplitude from peak to the end of the simulated AMPAR-mediated EPSCs obtained from synapses at 0,15,31,50,77, and $100 \mu \mathrm{m}$ and the unfiltered currents (same colors as for $\boldsymbol{E}$; 200 traces used for each data set; lines are parabolic fits to the data). $\mathbf{G}$, The $10-90 \%$ rise time of simulated AMPAR-mediated EPSC (circles) and estimated $\gamma$ (triangles; expressed as percentage of input value) plotted versus location of synapse. Lines are sigmoidal fits to the data. $\boldsymbol{H}$, Simulated mean EPSC (red) from synapse 1 generated by the realistic model using the kainate receptor kinetic scheme (slow kinetics, small $\gamma$ ) and superimposed on an experimentally recorded evoked kainate receptor-mediated EPSC. $\boldsymbol{I - K}$, Analysis of the effects of electrotonic location on NSFA of simulated kainate receptor-mediated EPSCs (as for $\boldsymbol{E}-\boldsymbol{G}$ ).

1996; Benke et al., 1998; Derkach et al., 1999; Dingledine et al., 1999; Smith and Howe, 2000; Smith et al., 2000). A bimodal distribution could suggest that cells predominantly exhibiting synaptic AMPA receptors of two distinct conductance properties 


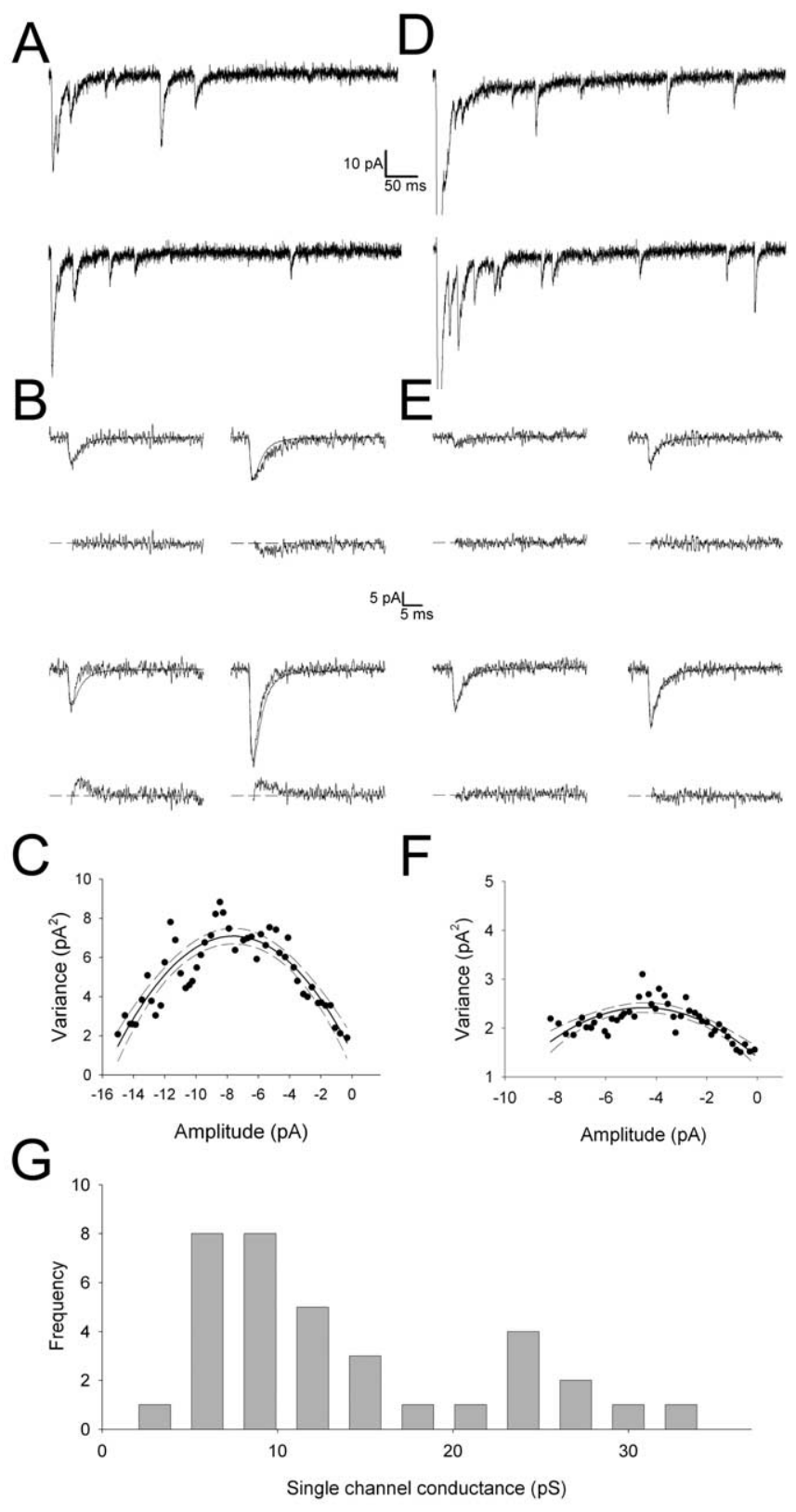

Figure 7. Estimation of the single-channel conductance $(\gamma)$ of AMPA receptors at thalamocortical synapses using NSFA of mEPSC fast. $_{\text {a }}$, Example of eEPSC and mEPSC $C_{\text {fast }}$ evoked in the presence of $\mathrm{Sr}^{2+}$ from a cell that exhibited a high $\gamma$ value. All data in $A-C$ are from the same cell. $\boldsymbol{B}$, Four individual evoked $\mathrm{mEPSC}_{\text {fast }}$ superimposed on the peak scaled mean waveform obtained from an average of $m E P S C_{\text {fast }}$ (top trace for each of the four pairs). The difference current for each is shown below. C, Binned squared difference current (variance) plotted versus current amplitude from the peak to the end of the EPSC obtained from a number of $\mathrm{mEPSC}_{\text {fast }}$ in this cell. The solid line is a parabolic fit to the data, with $95 \%$ confidence intervals indicated by dashed lines $\left(r^{2}=0.97\right.$; single-channel current, $-1.56 \pm 0.13 \mathrm{pA}$ for this fit). $\boldsymbol{D}-\boldsymbol{F}$, Data from a second example cell exhibiting low $\gamma$ (note that the synchronous eEPSC is offscale in the traces in D). For the parabolic fit, $r^{2}=0.99$; single-channel current, $-0.453 \pm 0.058 \mathrm{pA}$. G, Frequency histogram for AMPA receptor $\gamma$ obtained from $m E$ ESS $_{\text {fast }}$ in 35 cells.

exist, perhaps reflecting differences in the subunit composition or the phosphorylation state of the population of receptors in these cells.

mEPSC $_{\text {fast }} 10-90 \%$ rise time was not correlated with $\gamma$ (Fig. $8 A$ ), suggesting that the range of $\gamma$ values was not primarily attributable to differences in electrotonic filtering between cells (Benke et al., 2001) but rather generated by the intrinsic proper-
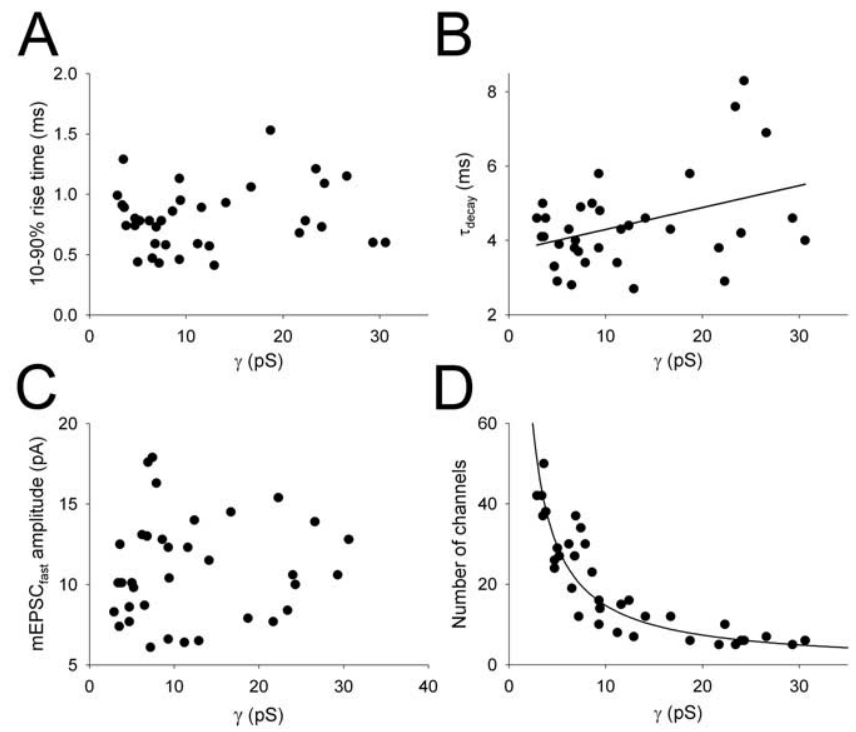

Figure 8. Summary of single-channel properties of AMPA receptors at developing thalamocortical synapses. $\boldsymbol{A}, \mathrm{mEPSC}_{\text {fast }} 10-90 \%$ rise time plotted versus $\gamma$ for all cells $(n=35)$. $\boldsymbol{B}$, $\mathrm{mEPSC}_{\text {fast }} \tau_{\text {decay }}$ plotted versus $\gamma$ for all cells $(n=35)$. The line is a linear regression, and $\tau_{\text {decay }}$ is weakly but significantly correlated with $\gamma(r=0.389 ; p<0.05)$. C, mEPSC $_{\text {fast }}$ amplitude plotted versus $\gamma$ for all cells $(n=35)$. $\boldsymbol{D}$, Estimated number of channels contributing to $\mathrm{mEPSC}_{\text {fast }}$ plotted versus $\gamma$ for all cells $(n=35)$. The line is a fit to the data of the following form: number of channels $=Q / \gamma \times 0.07$, iterated with $Q$ as the free parameter; $Q=10.3 \pm 0.45 \mathrm{pA}$; $r^{2}=0.94$. The number of channels is significantly correlated with $\gamma(p<0.0001)$.

ties of the AMPA receptor channels themselves. $\tau_{\text {decay }}$ showed a weak but significant positive correlation with $\gamma(r=0.389 ; p<$ 0.05) (Fig. $8 B$ ). mEPSC $_{\text {fast }}$ amplitude was not correlated with $\gamma$ (Fig. $8 C$ ), suggesting a reciprocal regulation of channel number (and/or their peak open probability) with $\gamma$ to maintain a relatively constant quantal amplitude. Indeed, when the number of channels contributing to mEPSC $_{\text {fast }}$ was estimated (by dividing mEPSC $_{\text {fast }}$ amplitude by $\gamma$ ), there was a strong negative correlation between this parameter and $\gamma$ (Fig. 8D). This relationship was well fit by the following function: number of channels $=$ $Q / \gamma \times 0.07$, where $\gamma \times 0.07$ (the driving force) is the singlechannel current, and $Q$ is the quantal amplitude. When this function was iterated to provide a best fit to the data, a predicted $Q$ of $10.3 \pm 0.45 \mathrm{pA}$ was obtained, very similar to $Q_{\mathrm{AMPA}}$ estimated from $\mathrm{mEPSC}_{\text {fast }}(10.7 \pm 0.5 \mathrm{pA})$. This strong relationship between number of channels and $\gamma$ suggests that some mechanism exists that scales AMPAR $\gamma$ and channel number to maintain a relatively constant quantal amplitude.

Little is known about the single-channel properties of native kainate receptors (Lerma et al., 2001). Furthermore, the singlechannel properties of synaptic kainate receptors have not been described, despite the dramatic differences in kinetics observed between kainate receptors expressed recombinantly or in extrasynaptic membranes and the properties of synaptically activated kainate receptors (Lerma et al., 2001; Lerma, 2003). To investigate the single-channel properties of synaptic kainate receptors, we performed NSFA of the slow eEPSCs, evoked independently of the AMPA receptor component using minimal stimulation (Fig. 9). Although we performed this analysis on a number of data sets, these currents typically exhibited very low variance during the decay (Fig. 9A), and estimates of $\gamma$ could only be obtained in a subset of cells, which likely reflects the upper limit of $\gamma$ for these receptors. From these cells, we obtained a value for $\gamma$ of $1.5 \pm 0.1$ pS $(n=3)$, approximately eight times smaller than the mean $\gamma$ 


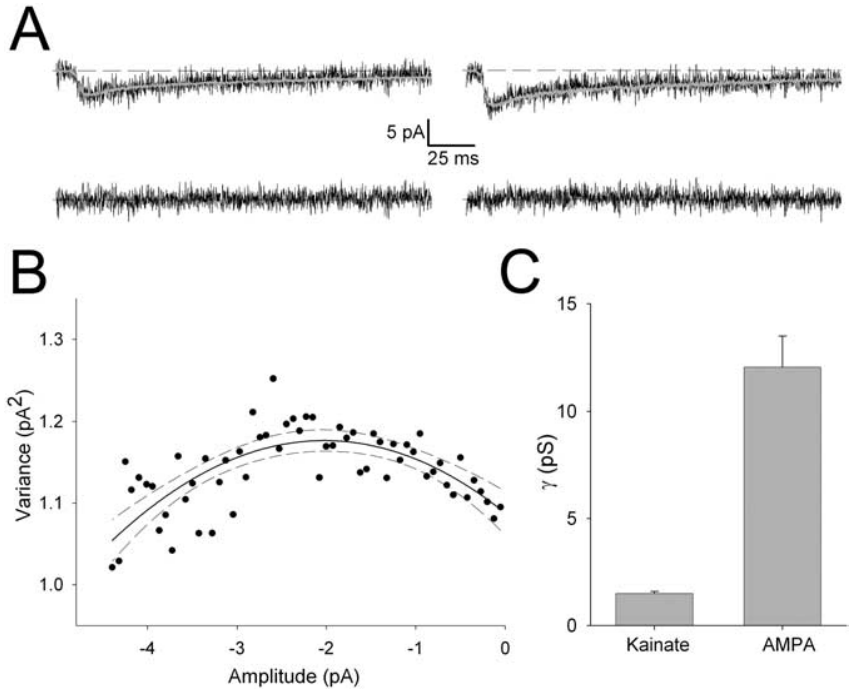

Figure 9. Single-channel properties of synaptically activated kainate receptors. $\boldsymbol{A}$, Example

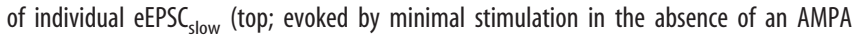
receptor-mediated component) superimposed on the peak scaled mean eEPSC ${ }_{\text {slow }}$ waveform for this cell (gray). Bottom traces are the difference currents for these traces. $\boldsymbol{B}$, Binned squared difference current (variance) plotted versus current amplitude from the peak to the end of the

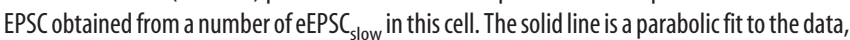
with $95 \%$ confidence intervals indicated by dashed lines $\left(r^{2}=0.99\right.$; single-channel current, $-0.0878 \pm 0.0139 \mathrm{pA}$ for this fit). $\boldsymbol{C}$, Summary data for $\gamma$ for kainate receptors $(n=3)$ and AMPA receptors ( $n=35$ ) at thalamocortical synapses (AMPA receptor data plotted from the same data set as shown in Figs. 7, 8).

value for AMPA receptors at this input $(12.1 \pm 1.4 \mathrm{pS} ; n=35)$ (Fig. 9C). This difference is similar to the difference in $Q$ for AMPA and kainate receptor-mediated transmission, suggesting that the small quantal size of kainate receptor-mediated EPSCs is essentially explained by the low single-channel conductance of these receptors at synapses.

Because NSFA of synaptic kainate receptors could only be performed on a small subset of cells, we also sought to address the properties of native kainate receptors in patches excised from the soma layer IV neurons. After obtaining a whole-cell recording, EPSCs were evoked that exhibited the dual-component decay typical of transmission mediated by AMPA and kainate receptors. However, in the same cells when an outside-out patch was excised and glutamate (10 $\mathrm{mm}$ ) was rapidly and briefly applied, only fast currents could be evoked that were fully blocked by the selective AMPA receptor antagonist GYKI53655 [1-(4aminophenyl)-3-methylcarbamoyl-4-methyl-3,4-dihydro7,8-methy lenedioxy-5H-2,3-benzodiazepine] ( $10 \mu \mathrm{M}$; data not illustrated). Thus, kainate receptors could not be detected in excised patches, precluding an analysis of their properties using this technique. We did, however, perform NSFA on the AMPARmediated currents to obtain an estimate of $\gamma$ for these receptors under conditions when there is no attenuation of $\gamma$ because of electrotonic filtering. This analysis produced an estimate of $\gamma$ of $15.7 \pm 1.7 \mathrm{pS}(n=6)$, a value $\sim 130 \%$ of that obtained from NSFA of mEPSC $_{\text {fast }}$. This indicates that, as suggested by the modeling, there is some attenuation in the estimate obtained for synaptic receptors. Previous studies indicate that somatic, dendritic, and synaptic AMPARs have very similar single-channel properties (Dingledine et al., 1999); however, we cannot rule out the possibility that somatic AMPARs in these neurons are different from synaptic receptors.

\section{Developmental regulation of AMPA and kainate receptor-mediated transmission}

The use of extracellular $\mathrm{Sr}^{2+}$ has allowed us to determine the quantal and single-channel properties of AMPA and kainate receptors at developing thalamocortical synapses. This enabled us to determine the relative contribution of these two types of synapse to the thalamocortical input and to investigate the mechanisms underlying the developmental regulation of kainate and AMPA receptor-mediated transmission. We estimated the quantal content $(m)$ of the AMPA $\left(m_{\text {AMPA }}\right)$ and kainate $\left(m_{\text {kainate }}\right)$ receptor-mediated components of the eEPSC (recorded before the application of $\mathrm{Sr}^{2+}$ ), using the quantal amplitude estimates obtained from the mEPSCs (in the presence of $\mathrm{Sr}^{2+}$ ). The size of the AMPA and kainate receptor-mediated components to the eEPSC was estimated using the biexponential fit to the decay, and $m$ was calculated by dividing the peak amplitude of each evoked component by its respective quantal amplitude estimated from the same cell (Fig. 10A). This analysis could be performed on the 13 cells in which both $Q_{\mathrm{AMPA}}$ and $Q_{\text {kainate }}$ could be determined. In the remainder of cells, no estimate for $Q_{\text {kainate }}$ could be obtained, and therefore the average $Q_{\text {kainate }}$ value (obtained from the 13 cells) was used to determine $m_{\text {kainate }}$ in these cells. Overall, $m_{\text {AMPA }}$ and $m_{\text {kainate }}$ were similar on average, although there was considerable variability between inputs (Fig. $10 \mathrm{~B}$ ).

To investigate the developmental regulation of the singlechannel and quantal properties of transmission, we analyzed various parameters in relation to postnatal age. In agreement with our previous work (Kidd and Isaac, 1999), we found that the kainate receptor-mediated component of the eEPSC decreased during this developmental period (percentage charge carried by the kainate receptor-mediated component is negatively correlated with age; $p<0.00005 ; n=42$ ) (Fig. 10C). Neither $Q_{\text {AMPA }}$ nor $Q_{\text {kainate }}$ changed with development (Fig. $10 D$ ), and similarly AMPA receptor $\gamma$ and number of AMPA receptors contributing to $\mathrm{mEPSC}_{\text {fast }}$ did not vary with development (Fig. 10E). However, the relative quantal contribution of AMPA and kainate receptors was strongly correlated with age. $m_{\mathrm{AMPA}}$ (expressed as a percentage of total $\mathrm{m}$ ) increased with age (correlation coefficient, $\left.r=0.53 ; p<5 \times 10^{-5} ; n=42\right)$, whereas $m_{\text {kainate }}$ decreased $(r=$ $-0.53 ; p<5 \times 10^{-5} ; n=42$ ) (Fig. $10 F$ ), producing a ratio of $m_{\text {kainate }} / m_{\text {AMPA }}$ that over all decreased during this developmental period $(r=-0.39 ; p<0.01 ; n=42)$ (Fig. 10G). Thus, during the first week of life, there is a developmental shift from kainate receptor- to AMPA receptor-mediated transmission. This is not attributable to a change in the quantal size of AMPA or kainate receptor-mediated events, nor is there a change in AMPA receptor single-channel properties. Instead, the developmental shift is caused by a change in the quantal contribution (a product of number of synapses and their probability of release) of the two types of input. Because we have shown that AMPA and kainate receptors are segregated to different synapses, this indicates that the developmental switch during the first week of life is attributable to a reduction in the number of kainate synapses and a reciprocal increase in the number of AMPA synapses that functionally contribute to transmission at the thalamocortical input to layer IV.

\section{Discussion}

Here we investigated the properties of AMPA and kainate receptors at thalamocortical synapses in barrel cortex during the first postnatal week. We show that both types of receptors mediate quantal synaptic events but not at the same synapses. AMPA receptor-mediated transmission has a large quantal amplitude, rapid kinetics, and a small charge transfer function compared 


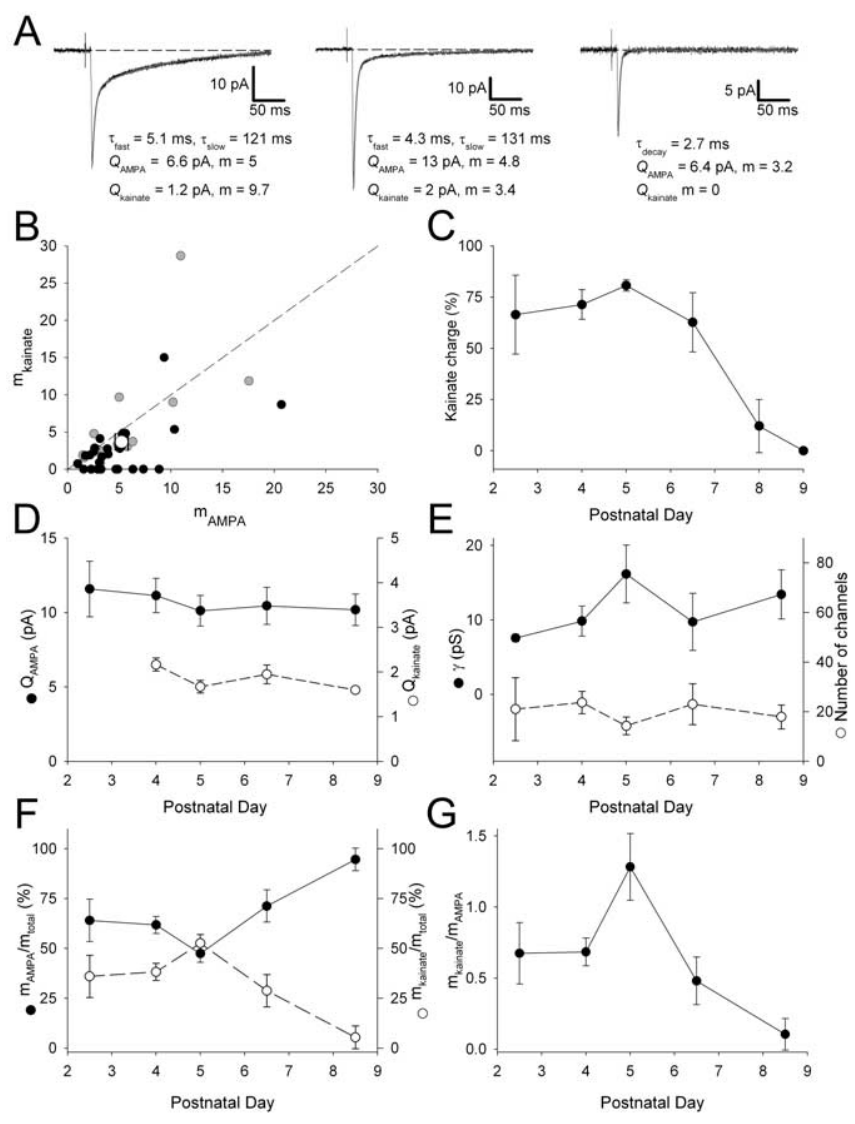

Figure 10. Developmental regulation of the quantal contribution of AMPA and kainate receptor-mediated transmission at the thalamocortical input. $A$, Examples of mean eEPSCs from three different cells showing the exponential fit to the decay (gray lines) and the decay time constants. The quantal amplitude $(Q)$ of the AMPA $\left(Q_{\text {AMPA }}\right)$ and kainate $\left(Q_{\text {kainate }}\right)$ components estimated from the evoked mEPSCs from the same cells is shown, and the calculated mean quantal content (the number of quanta released per trial; $m$ ) for each component is given. $\boldsymbol{B}$ Summary data plotting $m_{\text {kainate }}$ versus $m_{\text {AMPA }}$ for the eEPSC in all cells (dashed line is the line of unity). Black circles represent cells in which $Q_{\text {kainate }}$ could not be determined, so $m_{\text {kainate }}$ was determined using the mean $Q_{\text {kainate }}$ value $(n=29)$; gray circles represent cells in which values for both $Q_{A M P A}$ and $Q_{\text {kainate }}$ could be determined $(n=13)$, and mean value for all data pooled is also plotted (open circle). C, Developmental profile for the amount of charge carried by the kainate receptor-mediated component of the eEPSC (expressed as percentage of total EPSC charge; $\mathrm{P} 2-\mathrm{P} 3, n=5 ; \mathrm{P} 4, n=12 ; \mathrm{P} 5, n=10 ; \mathrm{P} 6-\mathrm{P} 7, n=6 ; \mathrm{P} 8, n=7 ; \mathrm{PP}, n=2)$. D, Developmental profiles for $\mathrm{Q}_{\text {AMPA }}$ (filled circles; $\mathrm{P2}-\mathrm{P} 3, n=5 ; \mathrm{P} 4, n=12 ; \mathrm{P} 5, n=10 ; \mathrm{P} 6-\mathrm{P} 7$, $n=6 ; P 8-P 9, n=9$ ) and $Q_{\text {kainate }}$ (open circles; note that no estimate for $Q_{\text {kainate }}$ was obtained for $\mathrm{P2}-\mathrm{P3} ; \mathrm{P} 4, n=3 ; \mathrm{P} 5, n=7 ; \mathrm{P} 6-\mathrm{P7}, n=2 ; \mathrm{P} 8-\mathrm{P} 9, n=1)$. For this and subsequent panels, data for $\mathrm{P2}-\mathrm{P3}, \mathrm{P6}-\mathrm{P7}$, and $\mathrm{P8}-\mathrm{P} 9$ are binned together. E, Developmental profiles for synaptic AMPA receptor $\gamma$ (filled circles; $\mathrm{P} 2-\mathrm{P} 3, n=2 ; \mathrm{P} 4, n=12 ; \mathrm{P} 5, n=8 ; \mathrm{P} 6-\mathrm{P} 7, n=4 ; \mathrm{P} 8-\mathrm{P} 9$, $n=9$ ) and number of channels (open circles; $\mathrm{P} 2-\mathrm{P} 3, n=2 ; \mathrm{P} 4, n=12 ; \mathrm{P} 5, n=8 ; \mathrm{P} 6-\mathrm{P} 7$, $n=4 ; \mathrm{P} 8-\mathrm{PP}, n=9$ ). $\boldsymbol{F}$, Developmental profiles for $m_{\text {AMPA }}$ expressed as a ratio of total $m$ (filled circles, solid lines; $\mathrm{P} 2-\mathrm{P} 3, n=5 ; \mathrm{P} 4, n=12 ; \mathrm{P} 5, n=10 ; \mathrm{P} 6-\mathrm{P} 7, n=6 ; \mathrm{P} 8-\mathrm{P} 9, n=9)$ and $m_{\text {kainate }}$ as a ratio of total $m$ (open circles, dashed lines; $P 2-P 3, n=5 ; P 4, n=12 ; P 5, n=10$; $\mathrm{P} 6-\mathrm{P7}, n=6 ; \mathrm{P8}-\mathrm{P9}, n=9)$. G, Developmental profile for $m_{\text {kainate }} / m_{\mathrm{AMPA}}(\mathrm{P} 2-\mathrm{P} 3, n=5 ; \mathrm{P} 4$, $n=12 ; \mathrm{P} 5, n=10 ; \mathrm{P} 6-\mathrm{P} 7, n=6 ; \mathrm{P} 8-\mathrm{P} 9, n=9$ ).

with kainate receptor-mediated transmission, which exhibits a small quantal amplitude, slow kinetics, and large charge transfer. AMPA receptors exhibit a relatively large $\gamma$ that varies over a considerable range, whereas kainate receptors have a low $\gamma$. Voltage-jump experiments and modeling indicate that the slow kinetics and small quantal amplitude of kainate receptormediated transmission are attributable to the intrinsic properties of the channel rather than effects of electrotonic filtering on fast AMPAR-like currents at remote synapses. The quantal contribution of AMPA receptor-mediated transmission increases and that of the kainate receptor-mediated component decreases during the first week of life; however, the quantal amplitude and singlechannel properties remain unchanged. Thus, during the first postnatal week, the number of AMPA synapses contributing to transmission increases, and the number of kainate synapses decreases.

\section{Contrasting quantal properties of AMPA and kainate receptor-mediated transmission}

The use of $\mathrm{Sr}^{2+}$ enabled us to establish that both AMPA receptors and kainate receptors mediate quantal events but do not participate in transmission at the same synapses. This provides strong evidence that the two receptor subtypes are not colocalized at these inputs. Although populations of purely kainate receptormediated mEPSCs have been observed in hippocampal CA3 pyramidal neurons and CA1 interneurons previously (Cossart et al., 2002), and kainate receptors mediate transmission between cone and off bipolar cells in retina in the absence of an AMPA receptor component (DeVries and Schwartz, 1999), complete segregation of the two receptors between synapses at the same input is unique, so far, to the developing thalamocortical input.

The quantal size of kainate receptor-mediated transmission is approximately one-sixth of that for AMPA receptor-mediated transmission; however, because of their slow kinetics, kainate receptors exhibit fivefold greater quantal charge transfer than AMPARs. Thus, of the two types of receptor, kainate receptors provide a greater synaptic drive than AMPARs. The prominent differences in the kinetic properties of AMPA and kainate receptor-mediated transmission are such that the two types of synapse likely encode very different features of afferent activity (Frerking and Ohliger-Frerking, 2002).

\section{Synaptic localization of kainate receptors}

There is much debate concerning the slow kinetics of synaptically evoked kainate receptor-mediated transmission. Kainate receptors expressed in recombinant systems exhibit fast kinetics very similar to AMPA receptors (Dingledine et al., 1999), whereas synaptic kainate receptors almost uniformly exhibit slow kinetics (Lerma et al., 2001). One hypothesis is that kainate receptors mediating the EPSC are located extrasynaptically and that their kinetics are determined by the slow arrival of transmitter. Although this has received some experimental support at hippocampal mossy fiber-CA3 synapses (Min et al., 1998), evidence against such an idea has been provided for other synapses (Bureau et al., 2000; Cossart et al., 2002), including developing thalamocortical synapses (Kidd and Isaac, 2001). Our present data provide additional support for a synaptic localization of kainate receptors at thalamocortical inputs; we show that kainate receptors are activated by quantal transmitter release, the kinetics of these events are very similar to evoked multiquantal EPSCs, and glutamate transport inhibition does not uncover an additional component of kainate receptor-mediated transmission. Moreover, our voltage-jump experiments show that kainate receptors underlying the EPSC are open for $>100 \mathrm{~ms}$ after the onset of the EPSC, directly demonstrating the slow nature of the channels underlying the kainate receptor-mediated EPSC.

\section{Single-channel properties of AMPA and kainate receptors on layer IV neurons}

AMPA receptors at thalamocortical synapses exhibited a wide range of $\gamma$. There was no correlation between $10-90 \%$ rise time and $\gamma$, although an influence of electrotonic location (which would be reflected in 10-90\% rise time) on the estimate of $\gamma$ is predicted by the modeling. However, it is likely that other pro- 
cesses are influencing AMPAR $\gamma$ that mask the effect of electronic location. For example, there are a number of subconductance states reported for AMPA receptors that contribute to the wide range of $\gamma$ values reported (Cull-Candy and Usowicz, 1987; Jahr and Stevens, 1987; Rosenmund et al., 1998; Derkach et al., 1999; Dingledine et al., 1999; Smith et al., 2000; Smith and Howe, 2000). Moreover, the relative amount of time AMPA receptors spend in each subconductance state has been shown to be regulated by receptor phosphorylation (Derkach et al., 1999) and agonist concentration (Rosenmund et al., 1998; Smith and Howe, 2000). In addition, AMPA receptor $\gamma$ is regulated by subunit composition and in particular the presence of edited glutamate receptor subunit 2 (GluR2) (Swanson et al., 1997; Dingledine et al., 1999). Thus, the wide range of $\gamma$ values observed in the present study suggests that AMPA receptors at thalamocortical synapses are under dynamic regulation by one or some of these mechanisms.

A striking feature of AMPA receptor-mediated transmission at developing thalamocortical synapses is that the wide variation in $\gamma$ is not reflected in mEPSC amplitude. Because both the $\gamma$ value and the amplitude of the averaged MEPSC were obtained from exactly the same records, one would expect a strong correlation between these two parameters if $\gamma$ is the major determinant of mEPSC amplitude. Indeed, we have shown previously in CA1 pyramidal neurons (Benke et al., 1998, 2001) that $\gamma$ directly determines EPSC amplitude even under conditions in which synapses at differing electrotonic locations and different quantal properties contribute to the averaged response. Thus, the lack of a correlation between $\gamma$ and mEPSC amplitude in the present study argues strongly for the existence of a mechanism that scales synaptic strength by trading off $\gamma$ with channel number. Indeed, our data show a strong negative correlation between these two parameters. In this regard, it is of interest to note that recent work has provided evidence for the regulation of AMPA receptor number in a mechanism involving the protein kinase A-dependent phosphorylation of GluR1 at developing thalamocortical synapses in barrel cortex (Lu et al., 2003).

Little is known about the single-channel properties of native kainate receptors. Studies on native kainate receptors in extrasynaptic membranes in young cerebellar granule cells indicates channels with femtosiemen or low picosiemen conductance, (Wyllie et al., 1993; Pemberton et al., 1998; Smith et al., 1999; Smith and Howe, 2000), whereas one study on layer V pyramidal cells suggests kainate receptors with a single-channel conductance of $\sim 8 \mathrm{pS}$ (Eder et al., 2003). However, the single-channel conductance of synaptic kainate receptors has not been investigated previously. Using NSFA, we obtained an estimate of singlechannel conductance of synaptic kainate receptors of $\sim 1.5 \mathrm{pS}$. Although our modeling suggests that the estimate for $\gamma$ using NSFA of synaptic currents is attenuated by $\sim 45 \%$, the degree of this attenuation is similar for both AMPA and kainate receptors, enabling a direct comparison of $\gamma$ for these two receptor types. Modeling indicates that the mean un-attenuated $\gamma$ value for AMPARs and kainate receptors at thalamocortical synapses in these neurons is $\sim 20$ and $\sim 3 \mathrm{pS}$, respectively. This difference essentially accounts for the difference in quantal amplitudes for these two components of transmission, as has been suggested previously for hippocampal CA1 interneurons based on coefficient of variation analysis of EPSCs (Frerking et al., 1998).

\section{Functional significance of the developmental shift from kainate to AMPA receptor-mediated transmission}

The contrasting quantal and single-channel properties of the two receptor subtypes indicates that the developmental conversion of kainate receptor- to AMPA receptor-mediated transmission that occurs during the first postnatal week will dramatically alter the properties of the thalamocortical input to the barrel cortex. The mechanism(s) by which transmission is switched from kainate receptor-mediated to AMPA receptor-mediated is still unclear. Our previous work has shown that induction of LTP causes a rapid switch from kainate to AMPA receptor-mediated transmission at this input (Kidd and Isaac, 1999). However, it is not known whether this reflects a downregulation of kainate receptors that are rapidly replaced by AMPA receptors at the same synapses or a silencing of kainate receptor-containing synapses and the unmasking of AMPA receptor-containing synapses. Because the switch from kainate to AMPAR-mediated transmission is rapid $(<5 \mathrm{~min})$ and coordinated (Kidd and Isaac, 1999), we suggest that this favors the former mechanism. In this regard, it is of interest to note that a recent study demonstrates that the molecular mechanisms exist for the rapid differential regulation of kainate and AMPA receptors at synapses (Hirbec et al., 2003).

The functional significance of a switch from kainate to AMPA receptor-mediated transmission is essentially unexplored. Our data suggest that, early in development, kainate receptors allow a large coincidence detection window but poorly transmit highfrequency afferent activity (Frerking and Ohliger-Frerking, 2002) of the sort associated with whisker activation (Fanselow and Nicolelis, 1999). The developmental switch to AMPA receptormediated transmission would reduce the coincidence detection window and thus may allow the faithful transmission of mature high-frequency whisker-evoked activity to layer IV.

\section{References}

Abdul-Ghani MA, Valiante TA, Pennefather PS (1996) $\mathrm{Sr}^{2+}$ and quantal events at excitatory synapses between mouse hippocampal neurons in culture. J Physiol (Lond) 495:113-125.

Agmon A, Connors BW (1991) Thalamocortical responses of mouse somatosensory (barrel) cortex in vitro. Neuroscience 41:365-379.

Bannister NJ, Nelson JC, Jack JJ (2002) Excitatory inputs to spiny cells in layers 4 and 6 of cat striate cortex. Philos Trans R Soc Lond B Biol Sci 357:1793-1808.

Benke TA, Lüthi A, Isaac JTR, Collingridge GL (1998) Modulation of AMPA receptor unitary conductance by synaptic activity. Nature 393:793-797.

Benke TA, Lüthi A, Palmer MJ, Wikström M, Anderson WW, Isaac JTR, Collingridge GL (2001) Mathematical modeling of non-stationary fluctuation analysis of synaptic AMPA receptors in branched structures. J Physiol (Lond) 537:407-420.

Bureau I, Dieudonne S, Coussen F, Mulle C (2000) Kainate receptormediated synaptic currents in cerebellar Golgi cells are not shaped by diffusion of glutamate. Proc Natl Acad Sci USA 97:6838-6843.

Castillo PE, Malenka RC, Nicoll RA (1997) Kainate receptors mediate a slow postsynaptic current in hippocampal CA3 neurons. Nature 388:182-186.

Chen S, Diamond JS (2002) Synaptically released glutamate activates extrasynaptic NMDA receptors on cells in the ganglion cell layer of rat retina. J Neurosci 22:2165-2173.

Colquhoun D, Jonas P, Sakmann B (1992) Action of brief pulses of glutamate on AMPA/kainate receptors in patches from different neurones of rat hippocampal slices. J Physiol (Lond) 458:261-287.

Cossart R, Esclapez M, Hirsch JC, Bernard C, Ben-Ari Y (1998) GluR5 kainate receptor activation in interneurons increases tonic inhibition of pyramidal cells. Nat Neurosci 1:470-478.

Cossart R, Epsztein J, Tyzio R, Becq H, Hirsch J, Ben-Ari Y, Crepel V (2002) Quantal release of glutamate generates pure kainate and mixed AMPA/ kainate EPSCs in hippocampal neurons. Neuron 35:147-159.

Crabtree JW, Isaac JTR (2002) New intrathalamic pathways allowing modality-related and cross-modality switching in the dorsal thalamus. J Neurosci 22:8754-8761.

Cull-Candy SG, Usowicz MM (1987) Multiple-conductance channels activated by excitatory amino acids in cerebellar neurons. Nature 325:525-528. 
Derkach V, Barria A, Soderling TR (1999) $\mathrm{Ca}^{2+} /$ calmodulin-kinase II enhances channel conductance of alpha-amino-3-hydroxy-5-methyl-4isoxazolepropionate type glutamate receptors. Proc Natl Acad Sci USA 96:3269-3274.

DeVries SH, Schwartz EA (1999) Kainate receptors mediate synaptic transmission between cones and "off" bipolar cells in a mammalian retina. Nature 397:157-160.

Diamond J, Jahr C (1997) Transporters buffer synaptically released glutamate. J Neurosci 17:4672-4687.

Dingledine R, Borges K, Bowie D, Traynelis SF (1999) The glutamate receptor ion channels. Pharmacol Rev 51:7-61.

Eder M, Becker K, Rammes G, Schierloh A, Azad SC, Zieglgansberger W, Dodt HU (2003) Distribution and properties of functional postsynaptic kainate receptors on neocortical layer V pyramidal neurons. J Neurosci 23:6660-6670.

Fanselow EE, Nicolelis MA (1999) Behavioral modulation of tactile responses in the rat somatosensory system. J Neurosci 19:7603-7616.

Feldman DE, Nicoll RA, Malenka RC, Isaac JTR (1998) Long-term depression at thalamocortical synapses in developing rat somatosensory cortex. Neuron 21:347-357.

Frerking M, Nicoll RA (2000) Synaptic kainate receptors. Curr Opin Neurobiol 10:342-351.

Frerking M, Ohliger-Frerking P (2002) AMPA receptors and kainate receptors encode different features of afferent activity. J Neurosci 22:7434-7443.

Frerking M, Malenka RC, Nicoll RA (1998) Synaptic activation of kainate receptors on hippocampal interneurons. Nat Neurosci 1:479-486.

Gil Z, Connors BW, Amitai Y (1999) Efficacy of thalamocortical and intracortical synaptic connections: quanta, innervation, and reliability. Neuron 23:385-397.

Goda Y, Stevens CF (1994) Two components of transmitter release at a central synapse. Proc Natl Acad Sci USA 91:12942-12946.

Häusser M, Roth A (1997) Estimating the time course of the excitatory synaptic conductance in neocortical pyramidal neurons using a novel voltage jump method. J Neurosci 17:7606-7625.

Hirbec H, Francis JC, Lauri SE, Braithwaite SB, Coussen F, Mulle C, Dev KK, Couthino V, Meyer G, Isaac JTR, Collingridge GL, Henley JM (2003) Rapid and differential regulation of AMPA and kainate receptors at hippocampal mossy fibre synapses by PICK1 and GRIP. Neuron 37:625-638.

Hollmann M, Heinemann S (1994) Cloned glutamate receptors. Annu Rev Neurosci 17:31-108.

Isaac JTR, Crair MC, Nicoll RA, Malenka RC (1997) Silent synapses during development of thalamocortical inputs. Neuron 18:269-280.

Jabaudon D, Shimamoto K, Yasuda-Kamatani Y, Scanziani M, Gahwiler BH, Gerber U (1999) Inhibition of uptake unmasks rapid extracellular turnover of glutamate of nonvesicular origin. Proc Natl Acad Sci USA 96:8733-8738.

Jahr CE, Stevens CF (1987) Glutamate activates multiple single channel conductances in hippocampal neurons. Nature 325:522-525.

Kidd FL, Isaac JTR (1999) Developmental and activity-dependent regulation of kainate receptors at thalamocortical synapses. Nature 400:569-573.

Kidd FL, Isaac JTR (2000) Glutamate transport blockade has a differential effect on AMPA and NMDA receptor-mediated synaptic transmission in the developing barrel cortex. Neuropharmacology 39:725-732.

Kidd FL, Isaac JTR (2001) Kinetics and activation of postsynaptic kainate receptors at thalamocortical synapses: role of glutamate clearance. J Neurophysiol 86:1139-1148.

Kidd FL, Coumis U, Collingridge GL, Crabtree JW, Isaac JTR (2002) A kainate autoreceptor is involved in regulating the dynamic properties of thalamocortical synapses during development. Neuron 34:635-646.

Kullmann DM (2001) Presynaptic kainate receptors in the hippocampus: slowly emerging from obscurity. Neuron 32:561-564.

Lerma J (2003) Roles and rules of kainate receptors in synaptic transmission. Nat Rev Neurosci 4:481-495.

Lerma J, Paternain AV, Rodriguez-Moreno A, Lopez-Garcia JC (2001) Molecular physiology of kainate receptors. Physiol Rev 81:971-998.

Lester RA, Clements JD, Westbrook GL, Jahr CE (1990) Channel kinetics determine the time course of NMDA receptor-mediated synaptic currents. Nature 346:565-567.

Li H, Rogawski MA (1998) GluR5 kainate receptor-mediated synaptic transmission in rat basolateral amygdala in vitro. Neuropharmacology $37: 1279-1286$.
Li P, Widing TJ, Kim SJ, Calejesan AA, Huettner JE, Zhou M (1999) Kainate-receptor-mediated sensory synaptic transmission in mammalian spinal cord. Nature 397:161-164.

Lu HC, She WC, Plas DT, Neumann PE, Janz R, Crair MC (2003) Adenylyl cyclase I regulates AMPA receptor trafficking during mouse cortical "barrel" map development. Nat Neurosci 6:939-947.

Lüthi A, Chittajallu R, Duprat F, Palmer MJ, Benke TA, Kidd FL, Henley JM, Isaac JTR, Collingridge GL (1999) Hippocampal LTD expression involves a pool of AMPA receptors regulated by the NSF-GluR2 interaction. Neuron 24:389-399.

Lüthi A, Wikström MA, Palmer MJ, Matthews P, Benke TA, Isaac JTR, Collingridge GL (2004) Bi-directional modulation of AMPA receptor unitary conductance by synaptic activity. BMC Neurosci 5:44.

Min MY, Rusakov DA, Kullmann DM (1998) Activation of AMPA, kainate, and metabotropic receptors at hippocampal mossy fiber synapses: role of glutamate diffusion. Neuron 21:561-570.

Oliet SH, Malenka RC, Nicoll RA (1996) Bidirectional control of quantal size by synaptic activity in the hippocampus. Science 271:1294-1297.

Pearce RA (1993) Physiological evidence for distinct $\mathrm{GABA}_{\mathrm{A}}$ responses in rat hippocampus. Neuron 10:189-200.

Pemberton KE, Belcher SM, Ripellino JA, Howe JR (1998) High-affinity kainate-type ion channels in rat cerebellar granule cells. J Physiol (Lond) 510:401-420.

Robinson HP, Sahara Y, Kawai N (1991) Nonstationary fluctuation analysis and direct resolution of single channel currents at postsynaptic sites. Biophys J 59:295-304.

Rosenmund C, Stern-Bach Y, Stevens CF (1998) The tetrameric structure of a glutamate receptor channel. Science 280:1596-1599.

Schmitz D, Mellor J, Frerking M, Nicoll RA (2001) Presynaptic kainate receptors at hippocampal mossy fiber synapses. Proc Natl Acad Sci USA 98:11003-11008.

Shimamoto K, Lebrun B, Yasuda-Kamatani Y, Sakaitani M, Shigeri Y, Yumoto N, Nakajima T (1998) DL-threo-beta-benzyloxyaspartate, a potent blocker of excitatory amino acid transporters. Mol Pharmacol 53:195-201.

Sigworth FJ (1980) The variance of sodium current fluctuations at the node of Ranvier. J Physiol (Lond) 307:97-129.

Silver RA, Cull-Candy SG, Takahashi T (1996) Non-NMDA glutamate receptor occupancy and open probability at a rat cerebellar synapse with single and multiple release sites. J Physiol (Lond) 494:231-250.

Smith TC, Howe JR (2000) Concentration-dependent substate behaviour of native AMPA receptors. Nat Neurosci 3:992-997.

Smith TC, Wang LY, Howe JR (1999) Distinct kainate receptor phenotypes in immature and mature mouse cerebellar granule cells. J Physiol (Lond) 517:51-58.

Smith TC, Wang L-W, Howe JR (2000) Heterogeneous conductance levels of native AMPA receptors. J Neurosci 20:2073-2085.

Spruston N, Jonas P, Sakmann B (1995) Dendritic glutamate receptor channels in rat hippocampal CA3 and CA1 pyramidal neurons. J Physiol (Lond) 482:325-352.

Swanson GT, Kamboj SK, Cull-Candy SG (1997) Single-channel properties of recombinant AMPA receptors depend on RNA editing, splice variation, and subunit composition. J Neurosci 17:58-69.

Taylor AM, Enoka RM (2004) Optimization of input patterns and neuronal properties to evoke motor neuron synchronization. J Comput Neurosci 16:139-157.

Traynelis SF, Silver RA, Cull-Candy SG (1993) Estimated conductance of glutamate receptor channels activated during EPSCs at the cerebellar mossy fiber-granule cell synapse. Neuron 11:279-289.

Vignes M, Collingridge GL (1997) The synaptic activation of kainate receptors. Nature 388:179-182.

Walker HC, Lawrence JJ, McBain CJ (2002) Activation of kinetically distinct synaptic conductances on inhibitory interneurons by electrotonically overlapping afferents. Neuron 35:161-171.

Wyllie DJ, Traynelis SF, Cull-Candy SG (1993) Evidence for more than one type of non-NMDA receptor in outside-out patches from cerebellar granule cells of the rat. J Physiol (Lond) 463:193-226.

Xu-Friedman MA, Regehr WG (2000) Probing fundamental aspects of synaptic transmission with strontium. J Neurosci 20:4414-4422.

Youngs IJ (2002) Exploring the universal nature of electrical percolation exponents by genetic algorithm fitting with general effective medium theory. J Phys D Appl Phys 35:3127-3137. 